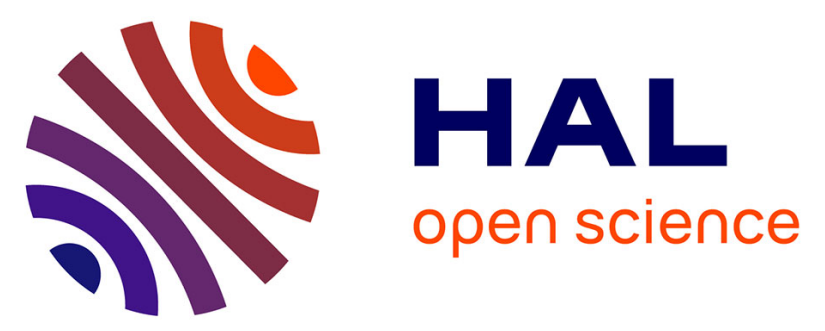

\title{
Does phenology explain plant-pollinator interactions at different latitudes? An assessment of its explanatory power in plant-hoverfly networks in French calcareous grasslands
}

Natasha de Manincor, Nina Hautekeete, Yves Piquot, Bertrand Schatz, Cédric

Vanappelghem, François Massol

\section{To cite this version:}

Natasha de Manincor, Nina Hautekeete, Yves Piquot, Bertrand Schatz, Cédric Vanappelghem, et al.. Does phenology explain plant-pollinator interactions at different latitudes? An assessment of its explanatory power in plant-hoverfly networks in French calcareous grasslands. Oikos, 2020, 129 (5), pp.753-765. 10.1111/oik.07259 . hal-02942299

\section{HAL Id: hal-02942299 \\ https://hal.science/hal-02942299}

Submitted on 6 Nov 2020

HAL is a multi-disciplinary open access archive for the deposit and dissemination of scientific research documents, whether they are published or not. The documents may come from teaching and research institutions in France or abroad, or from public or private research centers.
L'archive ouverte pluridisciplinaire HAL, est destinée au dépôt et à la diffusion de documents scientifiques de niveau recherche, publiés ou non, émanant des établissements d'enseignement et de recherche français ou étrangers, des laboratoires publics ou privés. 


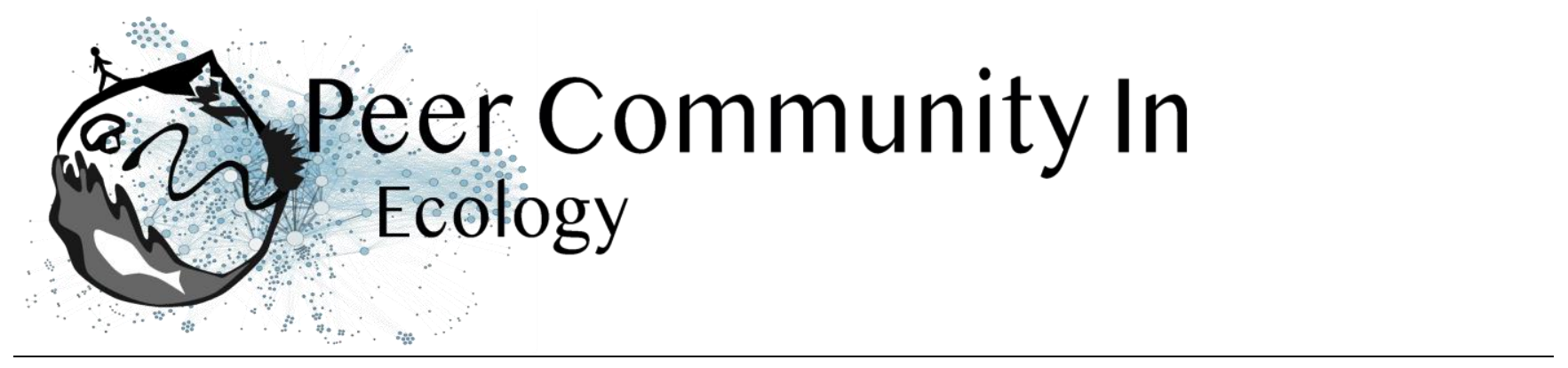

RESEARCH ARTICLE

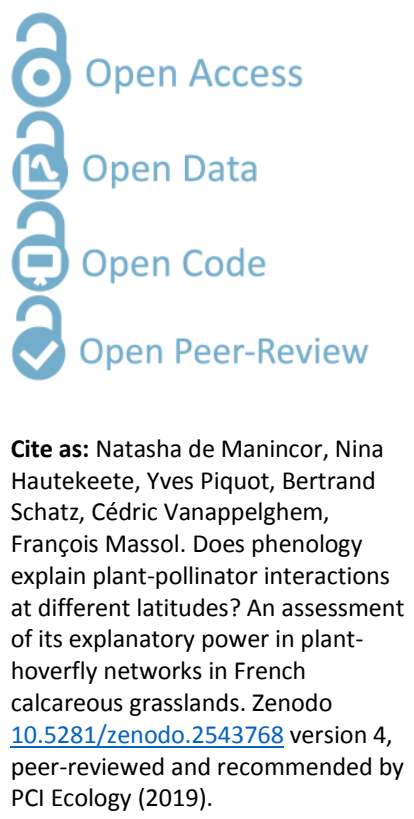

Posted: 22th November 2019

Recommender:

Anna Eklöf

Reviewers:

Ignasi Bartomeus and Phillip P.A.

Staniczenko

Correspondence:

natasha.demanincor@gmail.com
Does phenology explain plant-pollinator interactions at different latitudes? An assessment of its explanatory power in plant-hoverfly networks in French calcareous grasslands

Natasha de Manincor ${ }^{1}$, Nina Hautekeete', Yves Piquot ${ }^{1}$, Bertrand Schatz $^{2}$, Cédric Vanappelghem ${ }^{3}$, François Massol ${ }^{1,4}$

${ }^{1}$ Université de Lille, CNRS, UMR 8198 - Evo-Eco-Paleo, F-59000 Lille, France ${ }^{2}$ CEFE, EPHE-PSL, CNRS, University of Montpellier, University of Paul Valéry Montpellier 3, IRD, Montpellier, France

${ }^{3}$ Conservatoire d'espaces naturels Nord et du Pas-de-Calais, 160 rue Achille Fanien - ZA de la Haye, 62190 LILLERS

${ }^{4}$ Univ. Lille, CNRS, Inserm, CHU Lille, Institut Pasteur de Lille, U1019 - UMR 8204 - CIIL - Center for Infection and Immunity of Lille, F-59000 Lille, France

This article has been peer-reviewed and recommended by

Peer Community in Ecology

\section{ABSTRACT}

For plant-pollinator interactions to occur, the flowering of plants and the flying period of pollinators (i.e. their phenologies) have to overlap. Yet, few models make use of this principle to predict interactions and fewer still are able to compare interaction networks of different sizes. Here, we tackled both challenges using Bayesian Structural Equation Models (SEM), incorporating the effect of phenological overlap in six plant-hoverfly networks. Insect and plant abundances were strong determinants of the number of visits, while phenology overlap alone was not sufficient, but significantly improved model fit. Phenology overlap was a stronger determinant of plant-pollinator interactions in sites where the average overlap was longer and network compartmentalization was weaker, i.e. at higher latitudes. Our approach highlights the advantages of using Bayesian SEMs to compare interaction networks of different sizes along environmental gradients and articulates the various steps needed to do so.

Keywords: Bayesian model, interaction probability, latent block model, latitudinal gradient, mutualistic network, phenology overlap, species abundance, structural equation model. 


\section{Introduction}

Understanding how phenology determines species interactions is a central question in the case of mutualistic networks. In plant-pollinator networks, phenology shapes their temporal and spatial limits, thus defining the area and the period along the season in which interactions preferably occur (Olesen et al. 2011; Ogilvie \& Forrest 2017). Since plant and pollinator phenologies are not equally affected by changes in environmental cues, partial or total phenological mismatches can occur as a result of environmental changes such as climate change (Parmesan 2007; Rafferty 2017). Phenological advances indeed increase at higher latitudes, as a response to the acceleration of warming temperature along the same gradient (Post et al. 2018), increase phenological mismatch, and have the potential to threaten the synchrony needed for effective pollination (Hutchings et al. 2018). Such environmental changes can thus drastically alter pollinator interactions through modified temporal overlap between pollinators and their floral resources leading, in extreme cases, to local extinctions (Memmott et al. 2007) and the ensuing absence of the partner species at the location and/or time at which the interaction should have taken place (Willmer 2012; MillerStruttmann et al. 2015; Rafferty et al. 2015; Hutchings et al. 2018).

Because phenological match is crucial to plant-pollinator interactions, and thus ultimately to pollinators' fitness, pollinators have to adapt to phenological shifts either through interaction with other plant species (Rafferty et al. 2015) or through changes of their own phenology (Bartomeus et al. 2011). Phenology can then influence dynamical network properties, such as the stability and the coexistence of species, through changes in network topology (Encinas-Viso et al. 2012). Moreover, phenology predictably affects network compartmentalization as different phenophases likely correspond to different compartments when networks are considered on an annual scale (Martín González et al. 2012).

Despite considerable theoretical advances, there are few models available to predict the probability of interaction in plant-pollinator networks (Staniczenko et al. 2017; Cirtwill et al. 2019) and fewer still able to make comparisons between networks. Due to their complexity and variation among years (Chacoff et al. 2017), most studies of mutualistic networks have focused on predicting and comparing classic network metrics (nestedness, connectance, modularity, etc.) which are all influenced by network size, i.e. the number of plant and insect species (Fortuna et al. 2010; Staniczenko et al. 2013; Poisot \& Gravel 2014; Astegiano et al. 2015). Moreover, few studies have compared interaction networks along environmental gradients (Devoto et al. 2005; Schleuning et al. 2012; Sebastián-González et al. 2015; Pellissier et al. 
2017). In order to compare networks of different sizes, a better alternative is to switch from network-derived metrics to the comparison of the probability of interaction given by regression models, which can consider multiple factors and latent variables and assume that the sampled data are just part of a larger unobserved dataset (Grace et al. 2010).

Calcareous grasslands are characterized by highly diverse plant communities with a high proportion of entomophilous species (Baude et al. 2016), thus they are a convenient model for such studies. Most plant-insect pollinator networks involve bee species (Anthophila), but recent studies have also pointed out the importance of hoverflies (Diptera: Syrphidae), which pollinate a large spectrum of wild flowering species (Klecka et al. 2018a) and crops (Jauker \& Wolters 2008; Rader et al. 2011). They usually behave opportunistically, i.e. from being pollen generalists to specialists, only limited by morphological constraints (Iler et al. 2013; Klecka et al. 2018a; Lucas et al. 2018). Indeed, their generalist behaviour, at the species level, could be the result of individually specialized diets, since most pollen retrieved on hoverfly individuals usually comes from a single plant taxon (Lucas et al. 2018) and depends on flower availability and phenology (Cowgill et al. 1993; Colley \& Luna 2000; Lucas et al. 2018). Moreover, some hoverflies have preferences regarding plant colour, morphology and inflorescence height (Branquart \& Hemptinne 2000; Colley \& Luna 2000; Lunau 2014; Klecka et al. 2018b, a).

Here we study the consequences of environmental gradients on plant-pollinator interactions, focusing on how phenology overlap affects interactions between plants and insects in six calcareous grassland sites distributed along a latitudinal gradient. We obtained plant and insect phenologies, abundances, and interactions in all sites from April to October 2016. We modelled plant-pollinator interaction networks following a Bayesian Structural Equation Modelling approach (SEM) using latent variables, i.e. unobserved variables (Grace et al. 2010). SEM is a multivariate technique used to test several hypotheses in ecological studies. SEM analysis involves cause-effect equations to evaluate multiple causal relationship (Grace 2006; Eisenhauer et al. 2015) using observed and latent variables to explain some other observed variables (Grace 2006). SEM can be used to choose among competing models (Grace \& Bollen 2008). Thus, SEM are well suited for studying the complexity of ecological networks. To test whether phenology affects network compartmentalization, we looked for species subgroups using a latent block model (LBM) which is among the best clustering methods for weighted networks (Leger et al. 2015).

The comparison of 16 SEMs and the analysis of LBMs of sampled networks evinced that phenology overlap is an important determinant of plant-pollinator interactions, 
but is less informative than species abundances and performs heterogeneously among sites. Our results suggest that the use of SEMs to compare networks of different sizes along an environmental gradient is an innovative approach which can help understand the structure of plant-pollinator networks.

\section{Methods}

\section{Study sites}

We sampled plant and hoverfly species in six areas (Fig. S1) of 1 hectare each in different French regions: two sites in Hauts-de-France (Les Larris de Grouches-Luchuel, thereafter noted LAR, $50^{\circ} 11^{\prime} 22.5^{\prime \prime} \mathrm{N} 2^{\circ} 22^{\prime} 02.9^{\prime \prime} \mathrm{E}$ and Regional natural reserve Riez de Noeux les Auxi, noted R, 50 $14^{\prime} 51.85^{\prime \prime} \mathrm{N} 2^{\circ} 12^{\prime} 05.56^{\prime \prime} \mathrm{E}$, in départements Pas-de-Calais and Somme), two sites in Normandie (Château Gaillard - le Bois Dumont, noted CG, $49^{\circ} 14^{\prime} 7.782^{\prime \prime} \mathrm{N} \mathrm{1} 1^{\circ} 24^{\prime} 16.445^{\prime \prime E}$ and les Falaises d'Orival, noted FAL, 49 $04^{\circ} 40.08^{\prime \prime} \mathrm{N}$ $1^{\circ} 33^{\prime} 07.254 " \mathrm{E}$, départements: Eure and Seine Maritime) and two sites in Occitanie (Fourches, noted F, 43 $56^{\prime} 07.00^{\prime \prime} \mathrm{N} 3^{\circ} 30^{\prime} 46.1^{\prime \prime} \mathrm{E}$ and Bois de Fontaret, noted BF, $43^{\circ} 55^{\prime} 17.71 " \mathrm{~N} 3^{\circ} 30^{\prime} 06.06 " \mathrm{E}$, départment: Gard). The six sites are included in the European NATURA 2000 network, a network of preserved areas designated to protect a number of habitats and species representative of European biodiversity. The four sites in Hauts-de-France and Normandie are managed by the Conservatoire d'espaces naturels of Normandie, Picardie and Nord - Pas-de-Calais and the sites in Occitanie by the CPIE Causses méridionaux. We sampled each site once a month from April to October 2016, except for the site of Riez that was sampled from May to October.

\section{Plant-hoverfly observations and sampling}

To collect information at the community level, in each site and at each session we realized: (i) a botanic inventory of the flowering species, recorded their abundances and the total flower covering in the area and (ii) a pollinator sampling using a hand net along a variable transect walk.

Flowering plants were identified at the species level. We recorded the abundances of all flowering species. At first, we estimated the total percentage of surface covered by all flowering species in the selected area. We then estimated the relative abundance of each flowering species. We used Braun-Blanquet coefficients of abundancedominance, ranked from i to 5 (most abundant coefficient class) (van der Maarel 1975, 1979; Mucina et al. 2000), to rank flowering species. We converted the coefficients to percentage intervals and then in mean values of percentage cover classes (Table S1): coefficient $\mathbf{5}=\mathbf{7 5}-100 \%$, coeff $\mathbf{4}=50-75 \%$, coeff $3=25-50 \%$, coeff $\mathbf{2}=10-25 \%$, coeff $\mathbf{1}=$ 
$1-10 \%$, coeff $+=$ few individuals less than $<1 \%$, coeff $\boldsymbol{i}=1$ individual. All inventories were realized by the same surveyors to avoid biases.

Pollinator observations were performed by the same team of 3-5 persons each day. The surveyors walked slowly around any potential attractive resource patch included in the selected 1-hectare area for $4 \mathrm{~h}$ each day. We split the sampling period into 2 hours in the morning (about 10-12h) and 2 hours in the afternoon (about 14-16h) to cover the daily variability of both pollinator (bees and hoverflies, which are more active in the morning than in the afternoon; D'Amen et al. 2013) and flower communities. Sampling took place when we had suitable weather conditions for pollinators (following Westphal et al. 2008). We sampled all flower-visiting insects and we recorded observed interactions. All sampled insects were immediately put individually in a killing vial with ethyl acetate and were later prepared and pinned in the laboratory and identified at the species level by expert taxonomists. Even if we collected both bees and hoverflies, in this study we focus on hoverflies only (since at the moment of the study bees were not identified at the species level yet). Overall, we sampled for 41 days, equivalent to about 164 hours in the field (all the surveyors collected at the same time). For all analyses described here, we only used the list of visited herbaceous plant species and hoverflies which were found visiting a plant. Despite their rarity and even if hoverflies are known to prefer open flowers (Branquart \& Hemptinne 2000), we also considered the interactions between hoverflies and plant species of the Fabaceae family because we observed in the field that they visited Fabaceae species that were already opened by other insects, e.g. by large bee species, such as Eucera sp. (de Manincor, personal observation).

\section{Plant - hoverfly networks}

For each site, we constructed an interaction network consisting of all pairs of interacting plant and insect species, pooling data from all months. A pair of species $(i, j)$ was connected with intensity $v_{i j}$ when we recorded $v_{i j}$ visits of insect species $i$ on plant species $j$ in the site. We calculated the network specialization index, $\mathrm{H} 2$ ' (Blüthgen et al. 2006) using the $\mathrm{H} 2$ fun function implemented in the bipartite package (Dormann et al. 2009; R Core Team 2018). We obtained the $d$-value (Kullback-Leibler divergence between the interactions of the focal species and the interactions predicted by the weight of potential partner species in the overall network) and the $d$ max-value (maximum $d$-value theoretically possible given the observed number of interactions in the network) using the dfun function in the bipartite package (Dormann et al. 2009). We did not use the $d^{\prime}$ values provided by this package as they sometimes yielded spurious results based on the computation of the minimal $d$ value (e.g. reporting low $d^{\prime}$ for species with only one partner in the network).We then 
manually calculated the standardized specialization index $d^{\prime}$ (Blüthgen et al. 2006) for each plant and insect species as the ratio of the $d$-value to its corresponding $d m a x$ value.

We calculated the modularity of the network and the associated partition of species into modules using the cluster_leading_eigen method for modularity optimization implemented in the igraph package (Csardi \& Nepusz 2006; Newman 2006). Modularity optimization can help identify strong, simple divisions of a network into relatively independent sub-networks by looking for highly interconnected subnetworks. However, modules are not meant to inform about more subtle groupings among the species, e.g. particular avoidance of interactions between insects of group $A$ and plants of group 1. In order to detect such groups, we implemented latent block models (LBM) using the BM_poisson method for Poisson probability distribution implemented in the blockmodels package (Leger et al. 2015). Blocks are calculated separately for the two groups (insect and plant) based on the number of visits (i.e. a weighted network). The algorithm finds the best divisions of insects and plants through fitting one Poisson parameter in each block of the visit matrix, thus essentially maximizing the ICL (Integrated Completed Likelihood; Biernacki et al. 2000; Daudin et al. 2008). The LBM script is given in Supplementary Information (Appendix S3). All analyses were performed in $\mathrm{R}$ version 3.3.3 (R Core Team 2018).

\section{Plant and hoverfly abundances and phenology overlap}

We calculated plant abundance using information about the abundance-dominance recorded in the field following the methodology of Braun-Blanquet presented above. We transformed the coefficients of abundance in percentages (Table S1): we used the mean of the percentage corresponding to each class. We then calculated the relative abundance $\left(A_{P}\right)$ of each flowering plant species as the ratio of the focal species cumulated abundance to total flower abundance during its flowering season. For hoverflies, we used the recorded number of visiting individuals (total abundance) and their presence (recorded months) along the season to calculate their average abundance during months when they were present $\left(A_{H}\right)$.

We refer to plant phenology as their flowering period and insect phenology as the flying period. We considered only flowering plants which had been visited by pollinators. For the pollinators, we considered only hoverflies which were found in interaction. To build the species phenology tables for both plants and hoverflies, we merged the information provided by two sources of data (field data and the literature): we used the observed phenology of both plants and insects during the field session as the only source of information for plants (plants visited by insects and plants found in 
the botanic inventory in the site at that date), and we complemented the hoverfly phenology with information provided by the Syrph the Net Database (Speight et al. 2016). We then built the phenology overlap (PO) matrix based on the species phenology tables by calculating the number of phenologically active months that are shared by each pair of insect and plant species along the season.

\section{Bayesian Structural Equation Modelling (SEM)}

SEM is a confirmatory technique that involves cause-effect equations to evaluate multivariate hypotheses in ecological networks (Grace 2006). The primary interest of SEM analyses lies in its ability to compare different causal models between the same sets of explanatory and explained variables. Another important feature of SEM is that they can relate data through latent variables, i.e. variables which are not measured in the model and which represent underlying causes or effects, coupled with observed variables (Grace 2006; Grace et al. 2010). SEM can now be assessed using Bayesian approaches and parameters estimated using MCMC (Markov Chain Monte Carlo)(Grace et al. 2010; Fan et al. 2016).

In our study, we modelled hoverfly-plant interaction networks using a SEM approach (Fig. 1) with latent variables linking the number of visits per plant-pollinator species pair to abundance and phenology overlap (PO) data through a first latent table representing probabilities of interactions, another latent table representing the possible interactions between plant and pollinators (as a realization of the aforementioned interaction probability matrix), and a third latent table yielding the expected number of visits per plant-pollinator species pair (i.e. the intensity of interactions). We used the term latent tables to describe latent variables organized as insect $x$ plant tables, such as the expected number of visit matrix. 


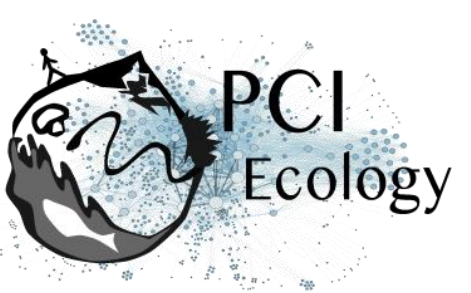

Figure 1. Summary diagram of the SEM model. We estimated 4 effects: the effect of plant abundance (AP $\rightarrow \lambda \mathrm{ij}$, coefficient $\lambda P$ ), the effect of insect (hoverflies) abundance on the intensity of visits ( $\mathrm{AH} \rightarrow \lambda_{\mathrm{ij}}, \lambda \mathrm{H}$ ), the effect of phenology overlap on the intensity of visits (PO $\rightarrow \lambda \mathrm{ij}, \lambda \mathrm{PO}$ ) and the effect of phenology overlap on the probability of interaction (PO $\rightarrow \mathrm{lij}$, $\mu \mathrm{PO}$ ). The phenology overlap (PO) is the number of phenologically active months that are shared by each pair of insect and plant species along the season. The intensity of visits $(\lambda i j)$ and the probability of interaction are latent variables in the model. Effect-i and effect-p are random effects calculated by the model which represent the insect and plant species identities. The lij (Possible interactions) is a binary variable and the Vij (visits observed) follow a Poisson distribution with an expected value given when the probability of interaction is predicted as "true". Rectangles represent observed variables while ovals represent unobserved influences.

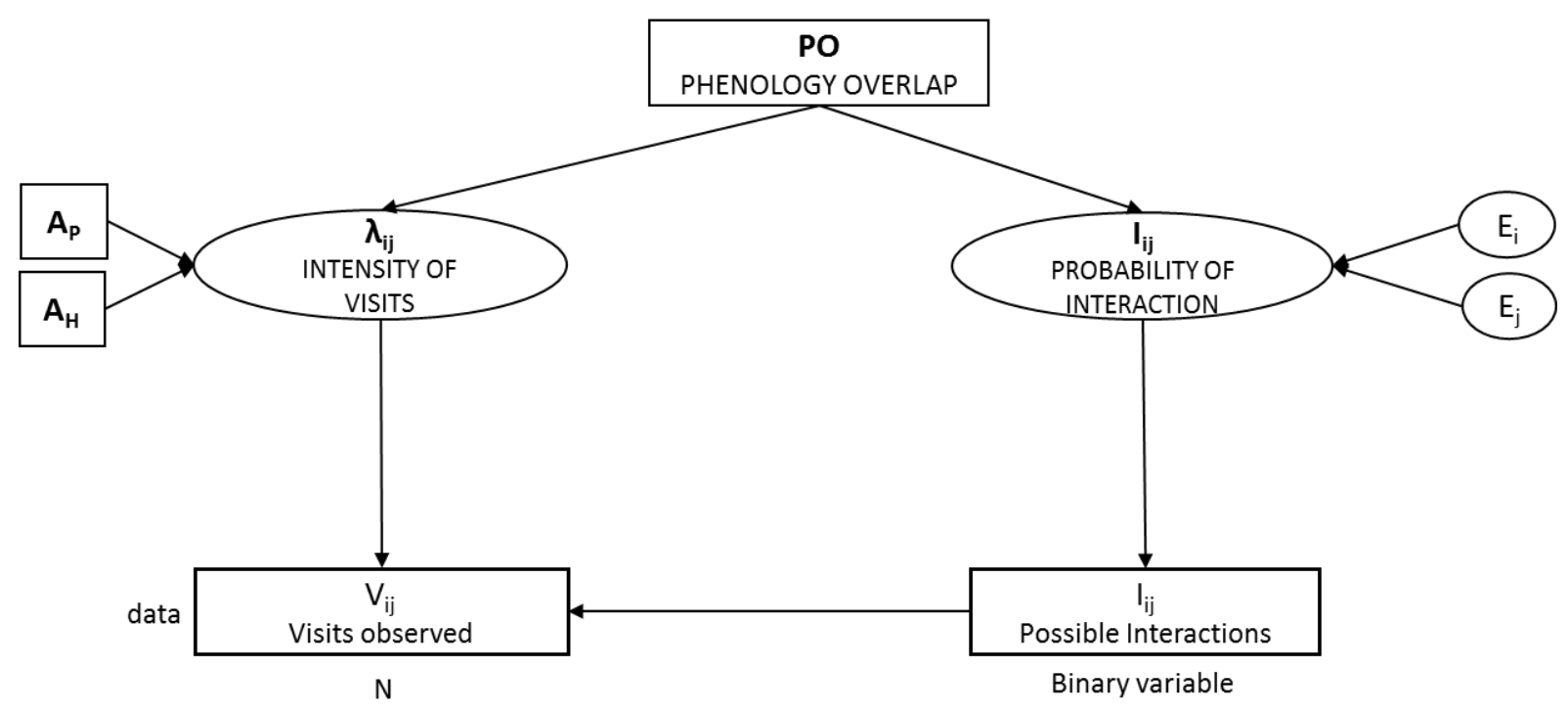




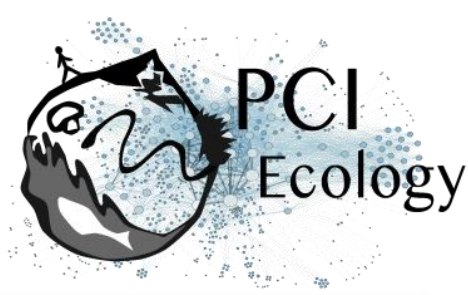

In this model, we considered that PO had an effect on possible interactions $\left(l_{i j}\right)$ and the number of visits $\left(\lambda_{i j}\right)$ - a longer overlap is intuitively expected to drive a higher probability of interaction and a larger number of visits. Interaction probabilities were also assumed to depend on two random effects (plant and insect species identities, $E_{i}$ and $E_{j}$ ), to represent heterogeneity of species degrees (i.e. the number of links) in the network. We modelled the possibility of interaction $I_{i j}$ between insect species $i$ and plant species $j$ (i.e. $l_{i j}=1$ when species $i$ and $j$ can interact) as a Bernoulli random variable of probability $\mu_{i j}$ given by:

$$
\operatorname{logit}\left(\mu_{i j}\right)=\mu_{0}+\mu_{P O} P O_{i j}+E_{i}+E_{j}
$$

where logit is the usual logistic transformation $\left(\log (x /(1-x)), \mu_{0}\right.$ is the intercept of this relation, $\mu_{P O}$ is the coefficient measuring the effect of $\mathrm{PO}$, and $E_{i}$ and $E_{j}$ are the random effects associated with insect species $i$ and plant species $j$ respectively.

The number of visits $V_{i j}$ was assumed to depend on plant and hoverfly abundances, as more abundant species are expected to be more often sampled (and thus more often recorded "in interaction"). Please note that we only linked abundances to the number of visits, $V_{i j}$, and not to the possibility of interaction $I_{i j}$, because the aim of the latter latent table is to capture "forbidden links", while detectability and sampling effects are supposed to be captured by the statistical model of the number of interactions. We integrated species abundances as predictor variables in order to assess the effect of PO on the number of visits on top of a "null model" that already includes sensible drivers of the numbers of visits, such as species abundances. $V_{i j}$ was modelled as a Poisson random variable to allow for sampling variability, with a conditional mean $\lambda_{i j}$ (the intensity of visits that can occur) given by:

$$
\log (\lambda i j)=\lambda_{0}+\lambda_{H} A_{H, i}+\lambda_{P} A_{P, j}+\lambda_{P O} \log \left(1+P O_{i j}\right)
$$

where $\lambda_{0}$ is the intercept of this relation, $\lambda_{H}$ is the coefficient measuring the effect of hoverfly abundance $A_{H}, \lambda_{\mathrm{P}}$ is that of plant abundance $A_{P}$, and $\lambda_{\mathrm{PO}}$ is the coefficient of the effect of PO.

Possible interactions $\left(I_{i j}\right)$ and the intensity of visits $\left(\lambda_{i j}\right)$ are multiplied to obtain the unconditional mean number of recorded visits, i.e. $V_{i j}$ is then obtained as a Poisson draw of mean $I_{i j} \lambda_{i j}$.

Overall we estimated four main parameters: the effect of phenology overlap on the probability of interaction ( $P O \rightarrow l_{i j}, \mu_{\mathrm{PO}}$ ), the effect of phenology overlap on the intensity of interactions ( $P O \rightarrow \lambda_{i j}, \lambda_{\mathrm{PO}}$ ), the effect of plant abundance on the intensity of interactions ( $A_{P} \rightarrow \lambda_{i j}$, coefficient $\lambda_{P}$ ) and the effect of insect (hoverflies) abundance on the intensity of interactions $\left(A_{H} \rightarrow \lambda_{i j}, \lambda_{H}\right)$. 


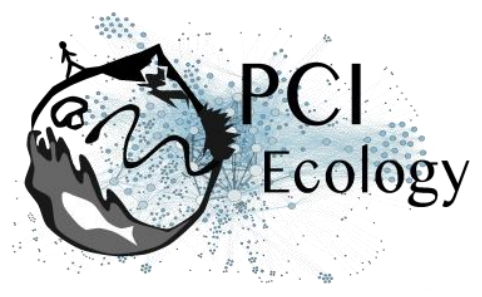

We used the jags function (R2 jags package), which provides an interface from $R$ to the JAGS library for Bayesian data analysis, to estimate model parameters. JAGS (Plummer 2003) uses a Markov Chain Monte Carlo algorithm to generate samples from the posterior distribution of the parameters. We ran two Markov chains with $10^{6}$ iterations per chain to check for model convergence. The code of the model is given in Supplementary Material (Appendix S1 and S2).

\section{Model and parameter comparison}

We estimated the 16 models that included all combinations of 0 and 4 of the abovementioned effects to understand which effects were more likely to play a role in the structuring of the network. The goodness-of-fit of these models were compared using the leave-one-out cross-validation criterion (LOO) calculated using the R package 100 using Pareto smoothed importance sampling for regularizing importance weights (Vehtari et al. 2017). The LOO criterion is a fully Bayesian method to compare models of different complexities and to estimate prediction accuracy using the log-likelihood evaluated at the posterior simulations of the parameter values (Vehtari et al. 2017). Models can thus be ranked according to their LOO scores, with the best model being the one with the lowest LOO value. The LOO criterion is analogous to the classic Akaike and Bayesian Information Criteria, which are used to compare frequentist models, but can instead be applied to Bayesian models, without suffering the instability issues of the Deviance Information Criterion which used to be the main information criterion for Bayesian models(Vehtari et al. 2017). To rank the models, we then calculated the $\triangle L O O$ (noted $\Delta_{i}$ ) as $\Delta_{i}=L O O_{i}-L O O_{\min }$ (following Burnham \& Anderson 2004), where $\angle O O_{\text {min }}$ is the minimum of the $L O O_{i}$ values among the 16 models. We used $\Delta_{i}$ to obtain model weights $\omega_{\mathrm{i}}$, following the Akaike weight methodology (Burnham \& Anderson 2002):

$$
\omega_{\mathrm{i}}=\frac{\mathrm{e}^{-\Delta_{\mathrm{i}} / 2}}{\sum \mathrm{e}^{-\Delta_{\mathrm{i}} / 2}}
$$

We then summed weights $\left(w_{H}\right)$ over all models that incorporated a given focal parameter to ascertain the plausibility of the effect associated to this parameter. We used this sum to evaluate the null hypothesis $(\mathrm{HO})$ that a given factor has no effect on the plant-pollinator interactions by comparing the sum of weights to null expectations, based on the fact that each tested effect is incorporated in exactly half of the tested models. The effect is considered plausible when $\mathrm{w}_{H}>0.5$, implausible otherwise, likely when $w_{H}>0.73$, and unlikely when it corresponds to a value of 0.27 or lower, following Massol et al. (2007). 


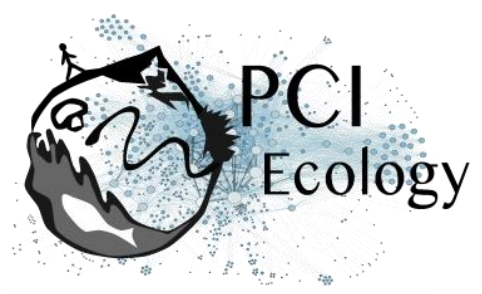

\section{Predictive power analysis}

We tested the predictive power of the models we built by making predictions for the $I_{i j}$ table and checking their validity using a binarized version of the visit table $V_{i j}$. Predictions were obtained by defining a threshold on interaction probability $\mu_{i j}$ : values found above the threshold were predicted as occurring interactions, values below the threshold as no interaction. The threshold probability value was found by maximizing the sum of model specificity and sensitivity. We computed accuracy statistics (sensitivity, specificity, omission rate, area under the ROC curve [AUC]) in two situations: (i) when predicting data for the site that was used to build the model (selfvalidation; e.g. predicting interaction data in the site of Riez based on the model developed for this site) and (ii) when predicting data for the other site from the same region (cross-validation; e.g. predicting data for the LAR site based on the model for the $\mathrm{R}$ site). We performed theses analyses using the SDMTOO Is package in R. We only used the set of best models $(\mathrm{LOO}<4)$ found for each site to predict the interactions in the other site through a multimodel averaging approach. We obtained the threshold probability using optim.tresh function with option max.sensitivity+specificity.

\section{Results}

\section{Plant-hoverfly networks and phenology overlap}

At the end of the field campaign we had collected 1584 hoverflies and recorded 1668 interactions between 76 hoverfly species and 115 plant species overall (Table 1, Table S2). The number of sampled hoverfly and plant species varied between sites and among regions. In Normandie we generally sampled a higher number of hoverflies than in the other two regions (Table 1 ) and the maximum number of visits recorded in the site of FAL was 47 (between Helophilus pendulus and Scabiosa columbaria, Fig. S2) and in the site of CG was 22 (between Eristalis tenax and S. columbaria and between Sphaerophoria scripta and Leontodon hispidus, Fig. 2). We observed the highest diversity of both plants and hoverflies in Occitanie and the lowest diversity of hoverflies in Hauts-de-France. Despite the high species diversity in Occitanie, the total number of interactions recorded in these sites (BF and $F$ ) is not the highest recorded in the field (Table 1): the maximum number of visits in the site of BF was 10 (between Spherophoria scripta and Helichrysum stoechas, Fig. S3) and 12 in the site of F (between Syrphus ribesii and Bellis perennis, Fig. 3). In the two southern sites we also recorded the lowest connectance values (BF: 0.07 and $F$ : 0.08 ) of all six sites, with the highest connectance observed in the site of $R$ ( $R$ 0.16; LAR 0.13; CG 0.13; FAL 0.12). The maximum number of visits recorded in the site of LAR was 12 (between Syrphus 


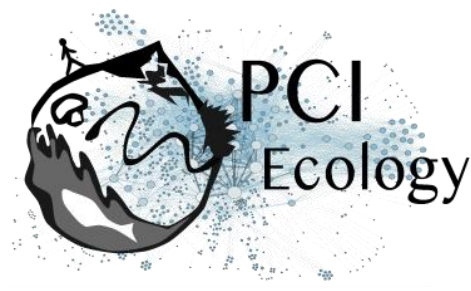

ribesii and L. hispidus, Fig. S4) and in the site of R was 17 (between Syritta pipiens and Asperula cynanchica, Fig. S5).

In spite of differences in diversity and the number of interactions, the overall level of specialization ( $\mathrm{H} 2$ index) did not show a high variation among the 6 networks (range: $0.32-0.37$ ). However, we found that the sites in Occitanie (BF and $F$ ) had a higher average degree of specialization ( $d^{\prime}$ ) for both insect (BF 0.63 and $F \quad 0.57$ ) and plant species (BF 0.58 and F 0.48). The sites in Occitanie also had a higher modularity (BF 0.51 and $F$ 0.48) than the ones in Normandie (CG 0.34 and FAL 0.23 ) and Hauts-deFrance (LAR 0.37 and R 0.34; Table 1). Given that these statistics only compare 6 sites, none of these assessments can be properly statistically tested, but the importance of the differences among sites is highly suggestive of a difference in average specialization and modularity. We found that plant phenology is generally shorter in all sites than that of hoverflies (Table 1 ). The phenology overlap was shorter in Occitanie (BF and F) than in the other sites (Table 1).

Illustrations of the block clustering provided by the LBM analysis (Latent Block Model) are shown in Fig. 2 and 3 in the main text and in Fig. S2 to S5 in Supplementary Information. We found different numbers of blocks in plants and hoverflies among sites: the BF site had 2 insect blocks and 2 plant blocks (Fig. S3); the F site had 4 of both (Fig. 3); the CG and R sites had 3 blocks for the plants and 4 blocks for the insects in (Fig. 2 and S5); the FAL site had 4 plant blocks and 3 insect blocks (Fig. S2); the LAR site had 3 blocks for the plants and 2 for the insects (Fig. S4). 


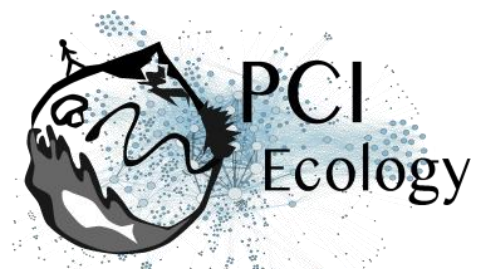

Table 1. Summary table of results obtained in each site (Bois de Fontaret [BF] and Fourches [F] in Occitanie, Château Gaillard [CG] and Falaises [FAL] in Normandie, Larris [LAR] and Riez [R] in Hauts-de-France). H2 ' and d' indices refer to specialization indices described by Blüthgen et al. (2006) and implemented in the R package bipartite (Dormann et al. 2009). The modularity score was obtained using the leadingeigenvector method described by Newman (2006) and implemented in the igraph package (Csardi \& Nepusz 2006). LBM refers to latent block modelling as implemented in the R package blockmodels (Leger et al. 2015).

\begin{tabular}{|c|c|c|c|c|c|c|c|c|c|c|c|c|c|c|}
\hline \multirow[b]{2}{*}{ Site } & \multirow[b]{2}{*}{ Region } & \multicolumn{4}{|c|}{ Collected data } & \multicolumn{3}{|c|}{ Specialization index } & \multicolumn{3}{|c|}{ Species phenology } & \multirow{2}{*}{$\begin{array}{l}\text { Modularity } \\
\text { analysis } \\
\text { modularity } \\
\text { score }\end{array}$} & \multicolumn{2}{|c|}{ LBM } \\
\hline & & $\begin{array}{c}\text { Sampled } \\
\text { insects }\end{array}$ & $\begin{array}{l}\text { Insect } \\
\text { species }\end{array}$ & $\begin{array}{l}\text { Plant } \\
\text { species }\end{array}$ & $\begin{array}{l}\text { Recorded } \\
\text { Interactions }\end{array}$ & $\begin{array}{l}\mathrm{H}^{\prime} \\
\text { index }\end{array}$ & $\begin{array}{l}\mathrm{d}^{\prime} \text { Insects } \\
\text { (average + } \\
\text { sd) }\end{array}$ & $\begin{array}{l}\text { d' Plants } \\
\text { (average + } \\
\text { sd) }\end{array}$ & $\begin{array}{c}\text { Insect } \\
\text { (average + } \\
\text { sd) }\end{array}$ & $\begin{array}{l}\text { Plant } \\
\text { (average + } \\
\text { sd) }\end{array}$ & $\begin{array}{c}\text { Phenology } \\
\text { overlap (PO) } \\
\text { (average + sd) }\end{array}$ & & blocks I & blocks P \\
\hline BF & Occitanie & 197 & 40 & 43 & 198 & 0.37 & $0.63 \pm 0.17$ & $0.58 \pm 0.17$ & $5.25 \pm 1.51$ & $2.14 \pm 1.04$ & $1.77 \pm 1.03$ & 0.53 & 2 & 2 \\
\hline $\mathrm{F}$ & Occitanie & 223 & 36 & 49 & 286 & 0.33 & $0.57 \pm 0.18$ & $0.48 \pm 0.19$ & $5.61 \pm 1.54$ & $2.08 \pm 1.13$ & $1.78 \pm 1.14$ & 0.48 & 4 & 4 \\
\hline CG & Normandie & 295 & 32 & 25 & 297 & 0.34 & $0.40 \pm 0.21$ & $0.47 \pm 0.18$ & $6.03 \pm 1.00$ & $3.28 \pm 1.24$ & $3.02 \pm 1.17$ & 0.34 & 4 & 3 \\
\hline FAL & Normandie & 363 & 34 & 30 & 374 & 0.32 & $0.40 \pm 0.18$ & $0.41 \pm 0.18$ & $6.06 \pm 1.13$ & $3.57 \pm 1.59$ & $3.23 \pm 1.51$ & 0.23 & 3 & 4 \\
\hline LAR & $\begin{array}{l}\text { Hauts-de- } \\
\text { France }\end{array}$ & 220 & 24 & 33 & 220 & 0.36 & $0.48 \pm 0.19$ & $0.45 \pm 0.15$ & $6.38 \pm 0.82$ & $3.18 \pm 1.38$ & $2.99 \pm 1.36$ & 0.37 & 2 & 3 \\
\hline $\mathrm{R}$ & $\begin{array}{l}\text { Hauts-de- } \\
\text { France }\end{array}$ & 286 & 22 & 29 & 293 & 0.32 & $0.39 \pm 0.16$ & $0.40 \pm 0.16$ & 5.550 .74 & $3.38 \pm 1.47$ & $3.11 \pm 1.45$ & 0.34 & 4 & 3 \\
\hline
\end{tabular}




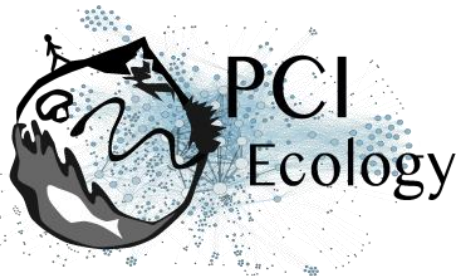

Figure 2. Block clustering provided by LBM in the site of Chateau Gaillard (CG, Normandie) overlaid on a heatmap of species phenology overlap. The LBM algorithm finds the best division for the group of insects and plants independently through fitting Poisson parameters in each block maximizing the likelihood (ICL). Insect species are displayed in rows and plant species in columns, following their degree (number of partners). The blocks of insects and the blocks of plants are separated by solid black lines. Colours correspond to the number of months that are shared by each pair of plant and insect species (PO, phenology overlap), with higher PO corresponding to darker colours. Numbers are the number of visits observed in the field for a given plant-insect pair. Complete species names are reported in Table S2.

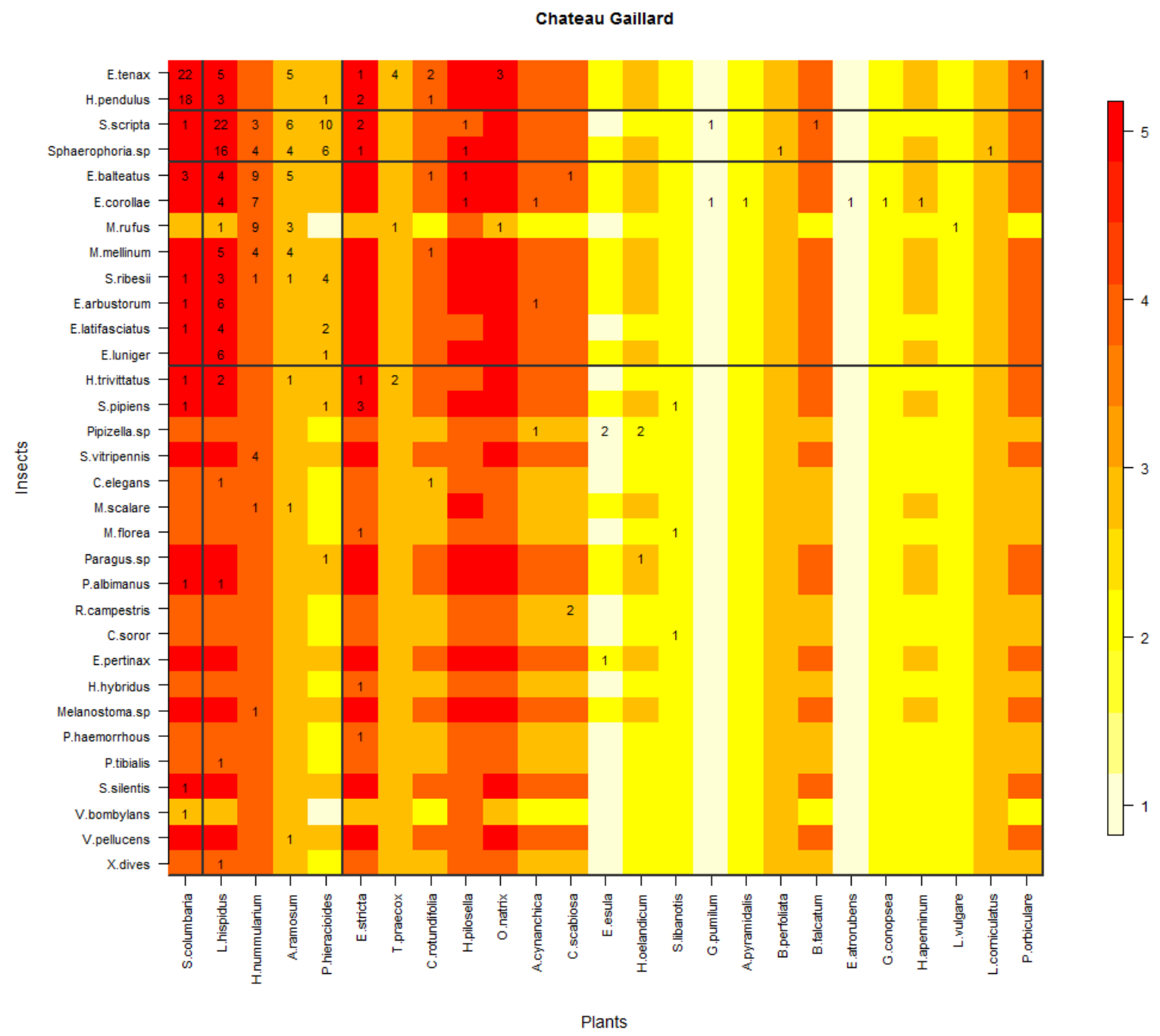




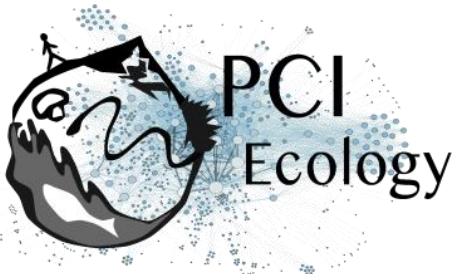

Figure 3. Block clustering provided by LBM in the site of Fourches ( $F$, Occitanie), overlaid on a heatmap of species phenology overlap. Insect species are displayed in rows and plant species in columns, following their degree (number of partners). The blocks of insects and the blocks of plants are separated by solid black lines. Colours correspond to the number of months that are shared by each pair of plant and insect species (PO, phenology overlap), with higher PO corresponding to darker colours. Numbers are the number of visits observed in the field for a given plant-insect pair. Complete species names are reported in Table S2.

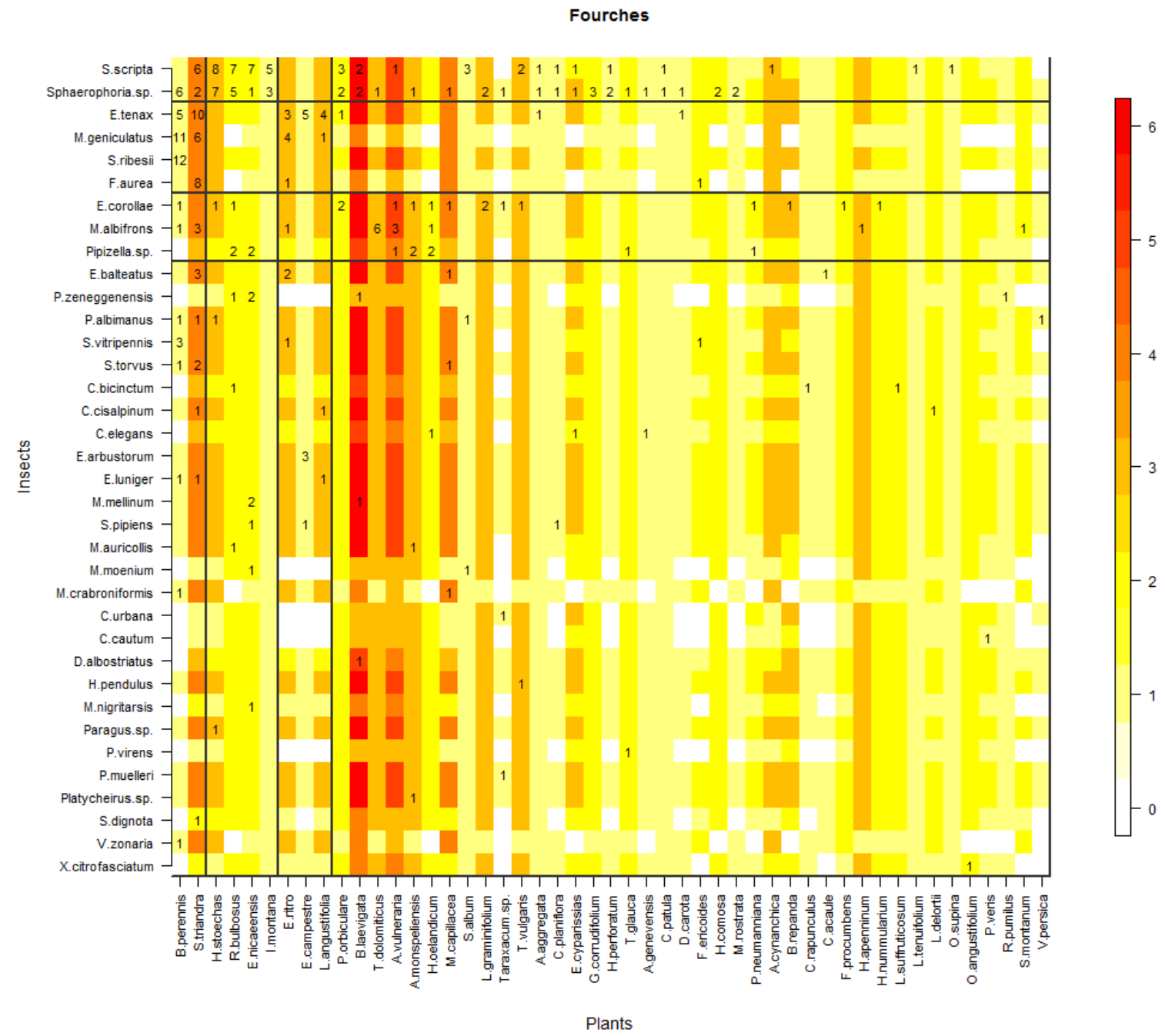




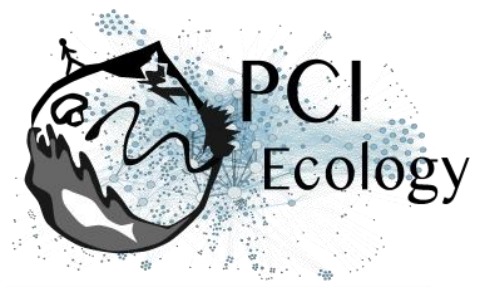

\section{Model ranking and comparison of parameters in each site}

For each site we compared the 16 models using the LOO criterion (Table 2, $\Delta$ LOO values). We found that models 1,2 and 4 had consistently better goodness-of-fit than the others. The model incorporating all effects except the effect of phenological overlap on the probability of interaction (Model 4: $\lambda_{i j} \sim A_{H}+A_{P}+$ PO, Table 2 ) was the best model in the sites of CG, FAL and LAR. In the two southern sites (BF and F), we found that the model incorporating all effects except that of phenological overlap on the intensity of visits (Model 1: $\lambda_{i j} \sim A_{H}+A_{P} / I_{i j} \sim P O$, Table 2), was the best one. The model incorporating all effects (Model $0: \lambda_{i j} \sim A_{H}+A_{P}+\mathrm{PO} / I_{i j} \sim \mathrm{PO}$, Table 2) was found as the best one only in the site of $\mathrm{R}$, but was a suitable model $(\Delta \mathrm{LOO}<4)$ in all the other sites (Table 2). We also compared the sum of model weights of the four parameters among sites (Table 2, Effects weight). We found that the effect of insect abundance on the intensity of interaction $\left(A_{H} \rightarrow \lambda_{i j}\right)$ is always likely (i.e. the sum of their weights is always higher than 0.73 , Table 2 ) and of large effect size in all sites (standardised coefficient higher than 1, Fig. 4). Likewise, we found that the effect of plant abundance on the intensity of interaction $\left(A_{P} \rightarrow \lambda_{i j}\right)$ was always likely and had large effect size in most part of sites, except in the site of $F\left(W_{H}=0.59\right.$, Table 2 ; standardised coefficient $=0.67$, Fig. 4). The effects of phenological overlap on the probability of interaction (PO $\rightarrow i_{i j}$ ) and the intensity of visits (PO $\rightarrow \lambda_{i j}$ ), however, had variable plausibility among sites. The effect of phenological overlap on the probability of interaction was likely only in half of the sites (Table 2 and Fig. 4). The effect of phenological overlap on the intensity of visits was not plausible only in the two southern sites (BF and F) and plausible in the other four sites (LAR, R CG and FAL, Table 2 and Fig. 4). In all sites, the standardised coefficients of $P O$ effects were always less than 1 , thus showing a low effect size of phenology on interaction probability and intensity (Fig. 4). 


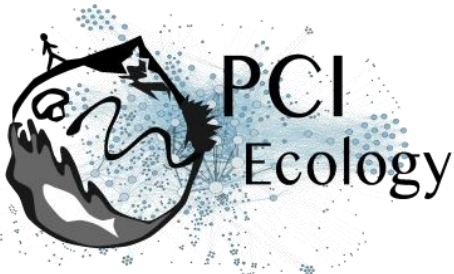

Table 2. (i) Comparison of SEM models using the leave-one-out cross-validation criterion (LOO); (ii) evidence ratios (ER) of model effects in each site. (i) Models are ranked depending on the number of parameters used (from 0 to 4). The best models are the ones with $\triangle L O O=0$ (underlined and bold values). The other suitable models are the ones with $\Delta \mathrm{LOO}<4$ (underlined and italic values). $\lambda_{i j}$ is the intensity of visits, $I_{i j}$ is the probability of interaction, $A_{H}$ is the insect abundance, $A_{P}$ is the plant abundance and PO is the phenology overlap. (ii) We compared 4 model effects: PO $\rightarrow l_{i j}$, effect of the phenology overlap on the probability of interaction; PO $\rightarrow \lambda_{i j}$ effect of the phenology overlap on the intensity of visits; $A_{H} \rightarrow \lambda_{i j}$ and $A_{P}$ $\rightarrow \lambda_{i j}$ effects of the hoverflies and plant abundances on the intensity of interaction. The $w_{H}$ limits for unlikelihood is 0.27 , plausibility 0.5 and likelihood 0.73 . Underlined and bold values represent the likely hypothesis only.

\begin{tabular}{|c|c|c|c|c|c|c|c|c|}
\hline & \multicolumn{6}{|c|}{ Sites } \\
\hline & & & $\mathrm{BF}$ & $\mathrm{F}$ & CG & FAL & LAR & $\mathrm{R}$ \\
\hline \multicolumn{2}{|r|}{ Model } & $\begin{array}{c}\mathrm{Nb} \text { of } \\
\text { parameters }\end{array}$ & \multicolumn{6}{|c|}{$\triangle L O O$ values } \\
\hline 0 & $\lambda_{i j} \sim A_{H}+A_{P}+\mathrm{PO} / I_{i j} \sim \mathrm{PO}$ & 4 & $\underline{2.98}$ & $\underline{2.04}$ & $\underline{3.54}$ & $\underline{2.54}$ & $\underline{2.86}$ & $\underline{0.00}$ \\
\hline 1 & $\lambda_{i j} \sim A_{H}+A_{P} / l_{i j} \sim P O$ & 3 & $\underline{0.00}$ & $\underline{0.00}$ & 36.75 & 64.04 & 10.37 & $\underline{2.90}$ \\
\hline 2 & $\lambda_{i j} \sim A_{P}+\mathrm{PO} / l_{i j} \sim \mathrm{PO}$ & 3 & 8.66 & 78.23 & 106.46 & 184.02 & 44.60 & 17.00 \\
\hline 3 & $\lambda_{i j} \sim A_{H}+\mathrm{PO} / l_{i j} \sim \mathrm{PO}$ & 3 & 6.63 & $\underline{1.71}$ & 8.09 & 73.62 & 11.24 & 11.42 \\
\hline 4 & $\lambda_{i j} \sim A_{H}+A_{P}+\mathrm{PO}$ & 3 & $\underline{2.86}$ & 8.06 & $\underline{0.00}$ & $\underline{0.00}$ & $\underline{0.00}$ & $\underline{2.24}$ \\
\hline 5 & $\lambda_{i j} \sim \mathrm{PO} / I_{i j} \sim \mathrm{PO}$ & 2 & 14.69 & 73.20 & 109.85 & 223.86 & 55.67 & 23.09 \\
\hline 6 & $\lambda_{i j} \sim A_{H} / l_{i j} \sim \mathrm{PO}$ & 2 & 1.45 & $\underline{1.31}$ & 33.53 & 119.04 & 27.23 & 19.76 \\
\hline 7 & $\lambda_{i j} \sim A_{P} / I_{i j} \sim \mathrm{PO}$ & 2 & 9.84 & 72.16 & 156.61 & 256.04 & 47.99 & 21.53 \\
\hline 8 & $\lambda_{i j} \sim A_{H}+\mathrm{PO}$ & 2 & 11.49 & 8.18 & 5.25 & 71.97 & 10.28 & 13.80 \\
\hline 9 & $\lambda_{i j} \sim A_{P}+\mathrm{PO}$ & 2 & 10.71 & 88.67 & 103.46 & 182.14 & 44.36 & 17.94 \\
\hline 10 & $\lambda_{i j} \sim A_{H}+A_{P}$ & 2 & 24.36 & 14.04 & 36.10 & 66.82 & 10.51 & 4.26 \\
\hline 11 & $I_{i j} \sim \mathrm{PO}$ & 1 & 11.78 & 68.52 & 154.26 & 272.98 & 64.12 & 32.39 \\
\hline 12 & $\lambda_{i j} \sim \mathrm{PO}$ & 1 & 19.99 & 86.20 & 108.46 & 219.66 & 54.64 & 25.73 \\
\hline 13 & $\lambda_{i j} \sim A_{H}$ & 1 & 25.58 & 14.41 & 36.12 & 123.30 & 28.27 & 22.78 \\
\hline 14 & $\lambda_{i j} \sim A_{p}$ & 1 & 32.99 & 87.70 & 157.74 & 256.39 & 48.82 & 22.87 \\
\hline \multirow[t]{2}{*}{15} & - & 0 & 34.39 & 83.89 & 155.68 & 274.80 & 64.78 & 33.52 \\
\hline & Model effects & & \multicolumn{6}{|c|}{ Effects weight $\left(W_{H}\right)$} \\
\hline & $\mathrm{PO} \rightarrow l_{i j}$ & & $\underline{0.88}$ & $\underline{0.98}$ & 0.15 & 0.22 & 0.20 & $\underline{0.74}$ \\
\hline & $\mathrm{PO} \rightarrow \lambda_{i j}$ & & 0.26 & 0.35 & $\underline{1.00}$ & 1.00 & $\underline{0.99}$ & $\underline{0.79}$ \\
\hline & $A_{H} \rightarrow \lambda_{i j}$ & & $\underline{0.99}$ & $\underline{1.00}$ & $\underline{1.00}$ & 1.00 & 1.00 & $\underline{1.00}$ \\
\hline & $A_{p} \rightarrow \lambda_{i j}$ & & $\underline{0.74}$ & 0.59 & $\underline{0.93}$ & $\underline{1.00}$ & $\underline{0.99}$ & $\underline{1.00}$ \\
\hline
\end{tabular}




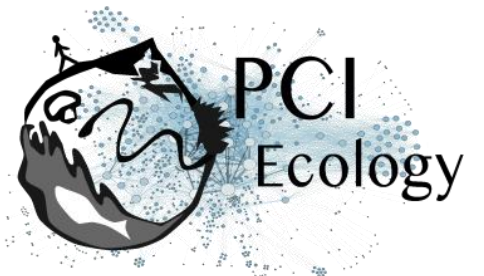

Figure 4. Summary diagram of the best models in all sites. The thickness of the arrows is scaled to Akaike weights (thin ER $<0.73$; thick ER $>0.73$, cf. Table 2). Standardised coefficients of the model average (computed based on the Akaike weighted model average) are reported next to the arrows. PO is the phenology overlap, $l_{i j}$ is the probability of interaction, $\lambda_{i j}$ is the intensity of visits, $A_{H}$ and $A_{P}$ are the hoverflies and plant abundances respectively.

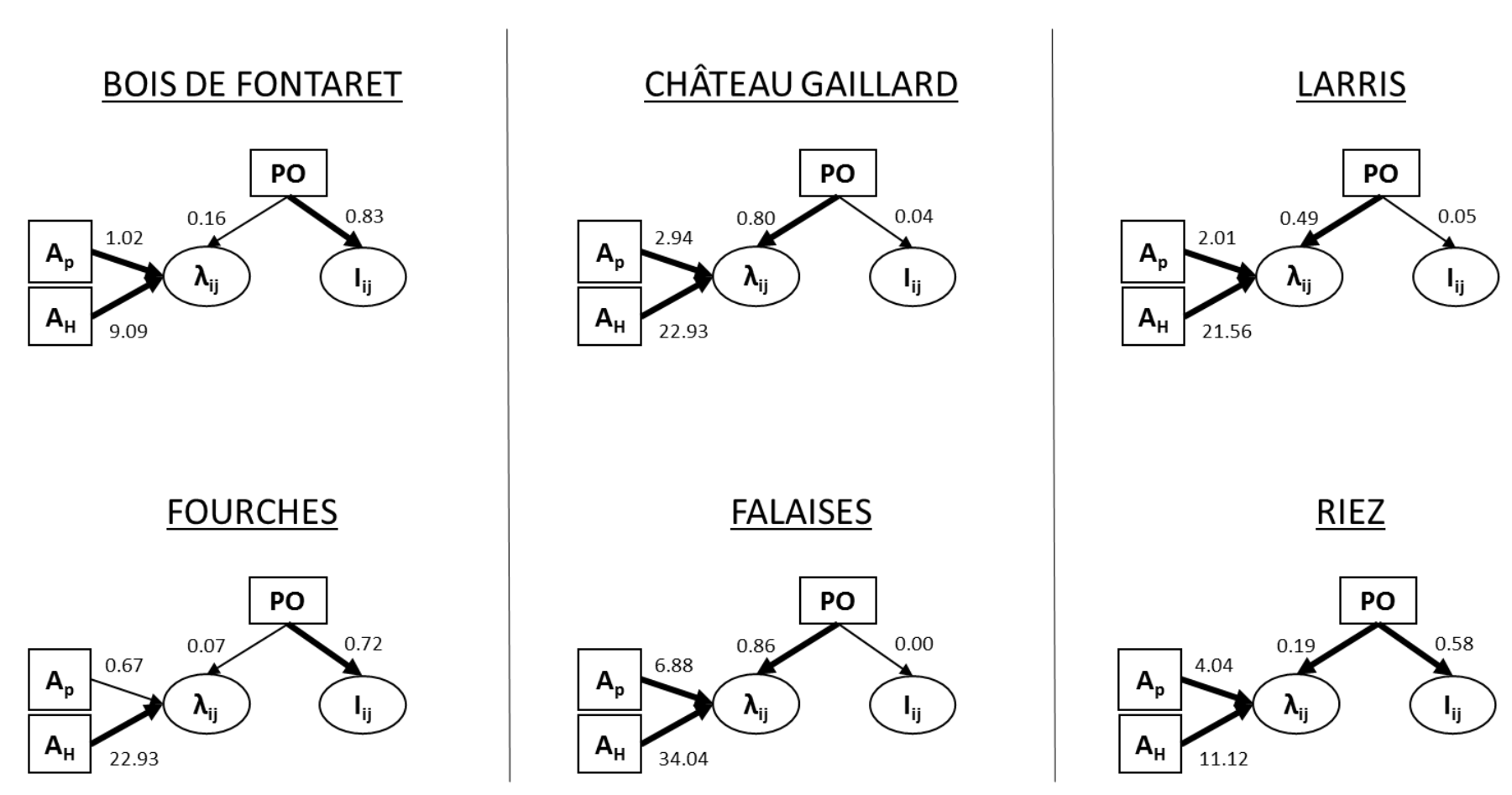




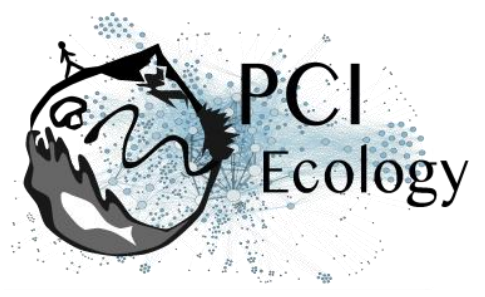

When assessing the predictive power of the best models, we observed that the sensitivity and specificity values, both for the self-validation and the cross-validation, were higher than 0.5 (Table S3), which means that the interactions predicted by the models are better than predicted by chance. While area under the curve (AUC) values were all higher than 0.75 for self-validation, cross-validation tests yielded intermediate values (AUC between 0.62 and 0.73 ), reflecting the fact that abundances and phenology are certainly not sufficient to make accurate predictions on the occurrence of plant-pollinator interactions.

\section{Discussion}

Latitude affects the seasonality, with advancing species phenologies at higher latitudes, and thus, can be a limiting factor for the phenological coupling of interacting species (Post et al. 2018). In this study we explored the effect of phenology overlap on a large network of species interactions in calcareous grasslands and how this effect could vary along a latitudinal gradient in France using empirical data on six planthoverfly networks. We identified plants and insects at the species level to build detailed interaction networks and hence avoid spurious generalisation levels. In order to better understand the determinants of variation in species interactions in space and time, we used the latitudinal gradient to consider variations linked to environmental cues and the entire flowering period to allow for seasonal variation (Valverde et al. 2016; Pellissier et al. 2017). One of the main problems of comparing networks along gradients is the dependence of network metrics on network size (Staniczenko et al. 2013; Astegiano et al. 2015; Tylianakis \& Morris 2017). In this study, to avoid the problem of comparing networks with different dimensions, we decided to focus on the determinants of the probability of interaction and the number of visits, rather than the overall structure. We employed Bayesian Structural Equation Models (SEM) which is an emergent approach increasingly used to investigate complex networks of relationship in ecological studies (Grace et al. 2010; Eisenhauer et al. 2015; Fan et al. 2016; Theodorou et al. 2017). In our study we used SEM to link the numbers of visits to phenology overlap (PO) and species abundance through latent probabilities of species interaction and expected numbers of visits per plant-pollinator species pair. We tested different models with variable numbers of effects and compared them in each site. In our models, we used species abundances to construct a sensible null model to test whether phenology overlap could help explain the probability and intensity of interactions when the effects of species abundances are already taken into account. In all sites, we found that models that included both PO and abundances had always better goodness-of-fit than models that included only abundances. 


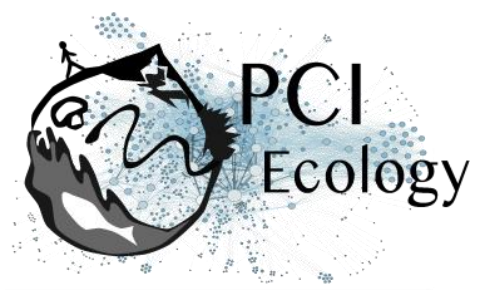

Abundances indeed provided a sensible null model since the goodness-of-fit of models that did not include abundances were always quite worse than the ones which did.

We also found that in all sites the most important factor affecting pollinator visits was insect abundance (Table 2). Likewise, we found that plant abundance was also a very important effect in most sites, except in the site of $F$ (Table 2). Since insect abundances are given by visitation data, it is not surprising that the intensity of interactions positively depends on these abundances. Species abundance often explain the linkage level in pollination network studies (Olesen et al. 2008; Bartomeus et al. 2016; Chacoff et al. 2017; Pellissier et al. 2017) but it is often associated with the length of the phenology to better assess the general properties of the interaction network (Vázquez et al. 2009; Olito \& Fox 2015). In accordance with this verbal prediction, we indeed found that the best models incorporated the effect of PO on either the probability or the intensity of interactions (Table 2), and the model that only considered species abundance (model 5 in Table 2) was not the best one in any site. Phenology overlap generally cannot predict the probability of interaction on its own (Encinas-Viso et al. 2012; CaraDonna et al. 2017). Our findings do agree with this general predicament since no site favoured a model that only incorporated PO effects and because these effects always display lower effect sizes than the other variables. However, our objective was not to compare the effect of phenology overlap to that of species abundance - for such an endeavour, one would need estimates of species abundances independent of visitation data. Because models which consider the effect of $\mathrm{PO}$ on the intensity and/or probability of interactions are the best models for all sites, this evinces a clear effect of PO. In our model, the effect of PO on the probability of interaction and the expected number of visits also vary along the latitudinal gradient (Fig. 4).In general, we observed that southern sites (BF and F) showed shorter plant phenology and phenology overlap (PO) than the other four sites (Table 1). In these sites, plant species richness is higher and fewer visits were sampled, probably because the presence of specialist species with short phenophases may increase the number of forbidden or undetected links (Olesen et al. 2011; Martín González et al. 2012). Conversely, in sites where plant phenology is longer, $\mathrm{PO}$ is longer too, as observed in Normandie and Hauts-de-France (CG, FAL, LAR and R, Table 1). Moreover, when plant richness and specialization are lower, a higher number of visits can be observed (Table 1) because generalist species could interact without constraints. Indeed, in Normandie and Hauts-de-France we found that the effect of phenology overlap on the intensity of visits was always likely (PO $\rightarrow \lambda_{i j}$, Table 2 ) and we observed higher numbers of interactions in the first two/three blocks of insects and plants which also corresponded to blocks with longer PO (Fig. 2, S2, S4 and S5). A higher phenological overlap is expected to drive a higher probability of interactions and a larger number of visits (Olesen et al. 2011). In Occitanie, we did not find any effect of PO on the number of 


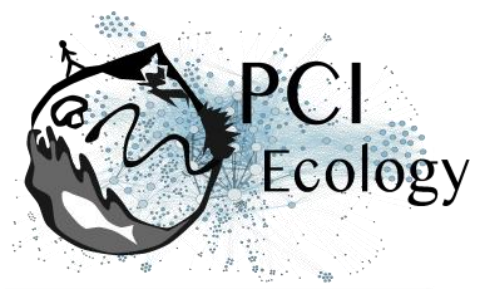

visits because the more densely visited blocks do not correspond to those with longer phenology overlap. Plant phenology can therefore drive the probability and the intensity of interactions in networks in which plant phenology is shorter, thus suggesting that hoverflies may undergo selection for behavioural flexibility in order to maintain synchrony with their foraging resources (ller et al. 2013; Ogilvie \& Forrest 2017).

We also found that modularity decreased along the latitudinal gradient, with richer sites (BF and F) displaying higher modularity (as in Sebastián-González et al. 2015) but also the lower connectance. In the two southern sites, higher modularity could be related to shorter phenologies and higher proportions of non-overlapping sets of species, which induce some form of temporal short-term specialisation (Lucas et al. 2018). However, modularity also seems to be influenced by species abundances and degrees (Schleuning et al. 2014), and is expected to increase with link specificity (Morente-López et al. 2018). Indeed, in these sites, species blocks match species degrees (Fig. 3 and S3), with generalist and specialist species forming separate blocks among both plants and insects (Martín González et al. 2012). With lower modularity and more generalist species, we expect a stronger relationship between phenology and the intensity of interactions because interactions are less influenced by insect preferences and more by seasonal rhythm and flower availability (Dormann et al. 2017). Thus, different phenophases might correspond to different compartments (Martín González et al. 2012; Morente-López et al. 2018), as observed in CG, FAL, LAR and $\mathrm{R}$ where higher overlap corresponded to higher numbers of observed visits. Although phenology improved model fit (Table 2), its effect size was modest (Fig. 4), which suggests that other types of data such as traits and phylogenies might help predict specific interactions. In our study, we did not consider competition among studied insect species or with other group of insects, such as bees which were present in all sites. Different types of pollinators with different abundances could have contextdependent effects on network topology (Valverde et al. 2016). Moreover, in our study we only considered as "true absence" of the interaction the lack of phenological coupling between species (i.e. plant and hoverfly species which are not present at the same moment along the season cannot interact). We did not consider "false absences", i.e. missing links, since not all the potential links among species are recorded in the field (Olesen et al. 2011) which may introduce bias in the estimation of the probability of interactions (Bartomeus et al. 2016; Cirtwill et al. 2019).

To conclude, plant phenology here drives the duration of the phenology overlap between plant and hoverflies, which in turn influences either the probability of interaction or the expected number of visits, as well as network compartmentalization. Longer phenologies correspond to less constrained interactions (lower modularity), 


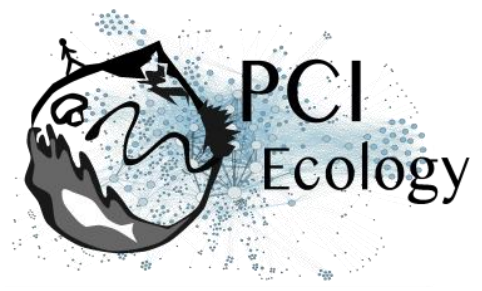

shorter phenologies to more constrained interactions (higher modularity), which in turn restrict the number of visits. Phenology overlap alone was not sufficient to explain interactions, as suggested elsewhere (CaraDonna et al. 2017). Plant and insect abundances played a substantial role to explain the number of visits (as in Chacoff et al. 2017) since abundances may affect partner choice (Trøjelsgaard et al. 2015). Our results, and the ability of the method used here to compare different effects on interaction patterns, suggest that the use of Bayesian SEM to compare networks of different sizes is a valuable tool which can help understand plant-pollinator networks (Eisenhauer et al. 2015). The use of latent variables can help predict the probability of interaction and the expected number of visits while avoiding circularity - the introduction of plant and insect specific random effects played the role of an implicit "degree" effect. Our results demonstrate the importance of considering differences in plant and insect phenologies to better predict their interactions in pollination networks at different latitudes. The use of morphological traits (e.g. tongue length, inter-tegular distance, ...) together with species richness and phylogenies, on top of variables already used, might improve the modelling of interactions and could help better understand some forbidden or missing links in richer communities or considering other pollinators (e.g. wild bees).

\section{Data accessibility}

The data supporting the results are archived on Zenodo (DOI: 10.5281/zenodo.2542845).

\section{Acknowledgements}

Financial support was provided by the ANR ARSENIC project (grant no. 14-CE02-0012), the Region Nord-Pas-de-Calais and the CNRS. We also thank Martin Speight for insect identification, Clément Mazoyer for informatic support and all the students who took part in the field campaign. This work is a contribution to the CPER research project CLIMIBIO. The authors thank the French Ministère de I'Enseignement Supérieur et de la Recherche, the Hauts-de-France Region and the European Funds for Regional Economical Development for their financial support. Version 4 of this preprint has been peer-reviewed and recommended by Peer Community In Ecology (https://doi.org/10.24072/pci.ecology.100034). 


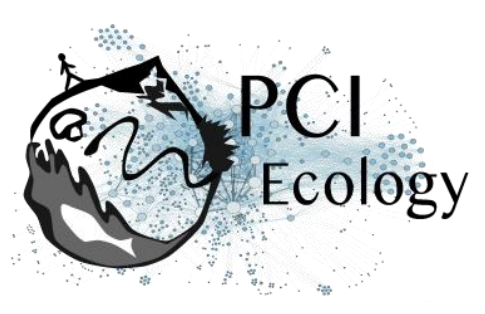

\section{Conflict of interest disclosure}

The authors of this preprint declare that they have no financial conflict of interest with the content of this article. François Massol and Bertrand Schatz are one of the PCI Ecology recommenders.

\section{References}

Astegiano, J., Massol, F., Vidal, M.M., Cheptou, P.O. \& Guimarães, P.R. (2015). The robustness of plant-pollinator assemblages: Linking plant interaction patterns and sensitivity to pollinator loss. PLoS One, 10, e0117243.

Bartomeus, I., Ascher, J.S., Wagner, D., Danforth, B.N., Colla, S., Kornbluth, S., et al. (2011). Climate-associated phenological advances in bee pollinators and beepollinated plants. Proc. Natl. Acad. Sci. U. S. A., 108, 20645-9.

Bartomeus, I., Gravel, D., Tylianakis, J.M., Aizen, M.A., Dickie, I.A. \& Bernard-Verdier, M. (2016). A common framework for identifying linkage rules across different types of interactions. Funct. Ecol., 30, 1894-1903.

Baude, M., Kunin, W.E., Boatman, N.D., Conyers, S., Davies, N., Gillespie, M.A.K., et al. (2016). Historical nectar assessment reveals the fall and rise of floral resources in Britain. Nature, 530, 85-88.

Biernacki, C., Celeux, G. \& Govaert, G. (2000). Assessing a mixture model for clustering with integrated completed likelihood. IEEE Trans. Pattern Anal. Mach. Intell., 22, 719-725.

Blüthgen, N., Menzel, F. \& Blüthgen, N. (2006). Measuring specialization in species interaction networks. BMC Ecol., 6, 9.

Branquart, E. \& Hemptinne, J. (2000). Selectivity in the exploitation of floral resources by hoverflies (Diptera: Syrphinae). Ecography (Cop.)., 23, 732-742.

Burnham, K.P. \& Anderson, D.R. (2002). Model Selection and Multimodel Inference $A$ Practical Information-Theoretic Approach. 2nd Editio. Springer-Verlag, New York.

Burnham, K.P. \& Anderson, D.R. (2004). Multimodel inference: Understanding AIC and BIC in model selection. Sociol. Methods Res., 33, 261-304.

CaraDonna, P.J., Petry, W.K., Brennan, R.M., Cunningham, J.L., Bronstein, J.L., Waser, N.M., et al. (2017). Interaction rewiring and the rapid turnover of plant pollinator networks. Ecol. Lett., 20, 385-394.

Chacoff, N.P., Resasco, J. \& Vázquez, D.P. (2017). Interaction frequency, network position, and the temporal persistence of interactions in a plant-pollinator network. Ecology, 99, 21-28.

Cirtwill, A.R., Eklof, A., Roslin, T., Wootton, K. \& Gravel, D. (2019). A quantitative framework for investigating the reliability of network construction. Methods Ecol. Evol., 10, 902-911.

Colley, M.R. \& Luna, J.M. (2000). Relative attractiveness of potential beneficial insectary plants to aphidophagous hoverflies (Diptera: Syrphidae). Environ. Entomol., 29, 1054-1059. 


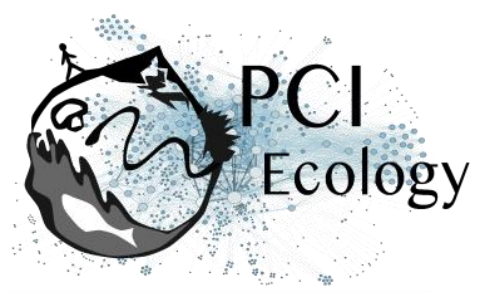

Cowgill, S.E., Wratten, S.D. \& Sotherton, N.W. (1993). The selective use of floral resources by the hoverfly Episyrphus balteatus (Diptera: Syrphidae) on farmland. Ann. Appl. Biol., 122, 223-231.

Csardi, G. \& Nepusz, T. (2006). The igraph software package for complex network research. InterJournal, Complex Sy, 1695.

D'Amen, M., Birtele, D., Zapponi, L. \& Hardersen, S. (2013). Patterns in diurnal cooccurrence in an assemblage of hoverflies (Diptera: Syrphidae). Eur. J. Entomol., $110,649-656$.

Daudin, J.J., Picard, F. \& Robin, S. (2008). A mixture model for random graphs. Stat. Comput., 18, 173-183.

Devoto, M., Medan, D. \& Montaldo, N.H. (2005). Patterns of interaction between plants and pollinators along an environmental gradient. Oikos, 109, 461-472.

Dormann, C.F., Fründ, J., Blüthgen, N. \& Gruber, B. (2009). Indices, graphs and null models: analyzing bipartite ecological networks. Open Ecol. J., 2, 7-24.

Dormann, C.F., Fründ, J. \& Schaefer, H.M. (2017). Identifying causes of patterns in ecological networks: opportunities and limitations. Annu. Rev. Ecol. Evol. Syst., 48, 12-20.

Eisenhauer, N., Bowker, M.A., Grace, J.B. \& Powell, J.R. (2015). From patterns to causal understanding: Structural equation modeling (SEM) in soil ecology. Pedobiologia (Jena)., 58, 65-72.

Encinas-Viso, F., Revilla, T.A. \& Etienne, R.S. (2012). Phenology drives mutualistic network structure and diversity. Ecol. Lett., 15, 198-208.

Fan, Y., Chen, J., Shirkey, G., John, R., Wu, S.R., Park, H., et al. (2016). Applications of structural equation modeling (SEM) in ecological studies: an updated review. Ecol. Process.

Fortuna, M.A., Stouffer, D.B., Olesen, J.M., Jordano, P., Mouillot, D., Krasnov, B.R., et al. (2010). Nestedness versus modularity in ecological networks: Two sides of the same coin? J. Anim. Ecol., 79, 811-817.

Grace, J.B. (2006). Structural Equation Modeling and Natural Systems. Cambridge University Press, New York.

Grace, J.B., Anderson, T.M., Olff, H. \& Scheiner, S.M. (2010). On the specification of structural equation models for ecological systems. Ecol. Monogr., 80, 67-87.

Grace, J.B. \& Bollen, K.A. (2008). Representing general theoretical concepts in structural equation models: The role of composite variables. Environ. Ecol. Stat., 15, 191-213.

Hutchings, M.J., Robbirt, K.M., Roberts, D.L. \& Davy, A.J. (2018). Vulnerability of a specialized pollination mechanism to climate change revealed by a 356-year analysis. Bot. J. Linn. Soc., 186, 498-509.

Iler, A., Inouye, D., Høye, T., Miller-Rushing, A., Burkle, L. \& Johnston, E. (2013). Maintenance of temporal synchrony between syrphid flies and floral resources despite differential phenological responses to climate. Glob. Chang. Biol., 19, 2348-2359.

Jauker, F. \& Wolters, V. (2008). Hover flies are efficient pollinators of oilseed rape. Oecologia, 156, 819-823.

Klecka, J., Hadrava, J., Biella, P. \& Akter, A. (2018a). Flower visitation by hoverflies (Diptera: Syrphidae) in a temperate plant-pollinator network. PeerJPreprints, 


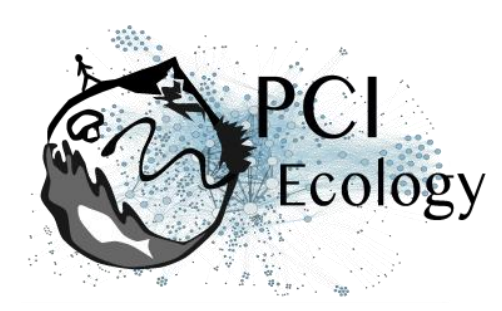

19, 780-785.

Klecka, J., Hadrava, J. \& Koloušková, P. (2018b). Vertical stratification of plantpollinator interactions in a temperate grassland. PeerJ, 6, e4998.

Leger, J.B., Daudin, J.J. \& Vacher, C. (2015). Clustering methods differ in their ability to detect patterns in ecological networks. Methods Ecol. Evol., 6, 474-481.

Lucas, A., Bodger, O., Brosi, B.J., Ford, C.R., Forman, D.W., Greig, C., et al. (2018). Generalisation and specialisation in hoverfly (Syrphidae) grassland pollen transport networks revealed by DNA metabarcoding. J. Anim. Ecol., 87, 10081021.

Lunau, K. (2014). Visual ecology of flies with particular reference to colour vision and colour preferences. J. Comp. Physiol. A Neuroethol. Sensory, Neural, Behav. Physiol., 200, 497-512.

van der Maarel, E. (1975). The Braun-Blanquet approach in perspective. Vegetatio, 30, 213-219.

van der Maarel, E. (1979). Transformation of cover-abundance values in phytosociology and its effects on community similarity. Vegetatio, 39, 97-114.

Martín González, A.M., Allesina, S., Rodrigo, A. \& Bosch, J. (2012). Drivers of compartmentalization in a Mediterranean pollination network. Oikos, 121, 2001-2013.

Massol, F., David, P., Gerdeaux, D. \& Jarne, P. (2007). The influence of trophic status and large-scale climatic change on the structure of fish communities in Perialpine lakes. J. Anim. Ecol., 76, 538-551.

Memmott, J., Craze, P.G., Waser, N.M. \& Price, M. V. (2007). Global warming and the disruption of plant-pollinator interactions. Ecol. Lett., 10, 710-717.

Miller-Struttmann, N.E., Geib, J.C., Franklin, J.D., Kevan, P.G., Holdo, R.M., Ebert-may, D., et al. (2015). Functional mismatch in a bumble bee pollination mutualism under climate change. Science, 349, 1541-4.

Morente-López, J., Lara-Romero, C., Ornosa, C. \& Iriondo, J.M. (2018). Phenology drives species interactions and modularity in a plant - flower visitor network. Sci. Rep., 8, 9386.

Mucina, L., Schaminée, J.H.J. \& Rodwell, J.S. (2000). Common data standards for recording relevés in field survey for vegetation classification. J. Veg. Sci., 11, 769-772.

Newman, M.E.J. (2006). Finding community structure in networks using the eigenvectors of matrices. Phys. Rev. E - Stat. Nonlinear, Soft Matter Phys., 74, 036104.

Ogilvie, J.E. \& Forrest, J.R. (2017). Interactions between bee foraging and floral resource phenology shape bee populations and communities. Curr. Opin. Insect Sci.

Olesen, J.M., Bascompte, J., Dupont, Y.L., Elberling, H., Rasmussen, C. \& Jordano, P. (2011). Missing and forbidden links in mutualistic networks. Proc. Biol. Sci., 278, 725-732.

Olesen, J.M., Bascompte, J., Elberling, H. \& Jordano, P. (2008). Temporal dynamics in a pollination network. Ecology, 89, 1573-1582.

Olito, C. \& Fox, J.W. (2015). Species traits and abundances predict metrics of plantpollinator network structure, but not pairwise interactions. Oikos, 124, 428- 


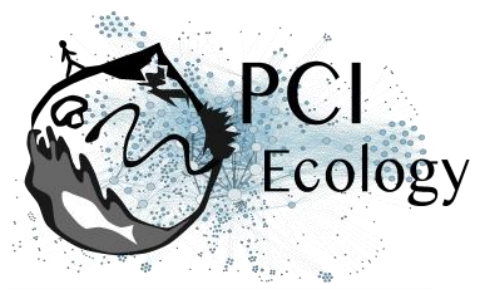

436.

Parmesan, C. (2007). Influences of species, latitudes and methodologies on estimates of phenological response to global warming. Glob. Chang. Biol., 13, 1860-1872.

Pellissier, L., Albouy, C., Bascompte, J., Farwig, N., Graham, C., Loreau, M., et al. (2017). Comparing species interaction networks along environmental gradients. Biol. Rev., 93, 785-800.

Plummer, M. (2003). JAGS: a program for analysis of Bayesian graphical models using Gibbs sampling.

Poisot, T. \& Gravel, D. (2014). When is an ecological network complex? Connectance drives degree distribution and emerging network properties. PeerJ, 2, e251.

Post, E., Steinman, B.A. \& Mann, M.E. (2018). Acceleration of phenological advance and warming with latitude over the past century. Sci. Rep., 8, 3927.

R Core Team. (2018). R: A language and environment for statistical computing. $R$ Foundation for Statistical Computing, Vienna, Austria. URL https://www.Rproject.org/.

Rader, R., Edwards, W., Westcott, D.A., Cunningham, S.A. \& Howlett, B.G. (2011). Pollen transport differs among bees and flies in a human-modified landscape. Divers. Distrib., 17, 519-529.

Rafferty, N.E. (2017). Effects of global change on insect pollinators: multiple drivers lead to novel communities. Curr. Opin. Insect Sci.

Rafferty, N.E., CaraDonna, P.J. \& Bronstein, J.L. (2015). Phenological shifts and the fate of mutualisms. Oikos, 124, 14-21.

Schleuning, M., Fru, J., Klein, A., Abrahamczyk, S., Albrecht, M., Andersson, G.K.S., et al. (2012). Report specialization of mutualistic interaction networks decreases toward tropical latitudes, 1925-1931.

Schleuning, M., Ingmann, L., Strauß, R., Fritz, S.A., Dalsgaard, B., Matthias Dehling, D., et al. (2014). Ecological, historical and evolutionary determinants of modularity in weighted seed-dispersal networks. Ecol. Lett., 17, 454-463.

Sebastián-González, E., Dalsgaard, B., Sandel, B. \& Guimarães, P.R. (2015). Macroecological trends in nestedness and modularity of seed-dispersal networks: Human impact matters. Glob. Ecol. Biogeogr., 24, 293-303.

Speight, M.C.D., Castella, E., Sarthou, J.-P. \& Vanappelghem, C. (2016). StN 2016. In: Syrph the Net on CD, Issue 11. Speight, M.C.D., Castella, E., Sarthou, J.-P. \& Vanappelghem, C. (Eds.) Syrph the Net Publications, Dublin.

Staniczenko, P.P.A., Kopp, J.C. \& Allesina, S. (2013). The ghost of nestedness in ecological networks. Nat. Commun., 4, 1391-1396.

Staniczenko, P.P.A., Lewis, O.T., Tylianakis, J.M., Albrecht, M., Coudrain, V., Klein, A.M., et al. (2017). Predicting the effect of habitat modification on networks of interacting species. Nat. Commun., 8.

Theodorou, P., Albig, K., Radzevičiūtè, R., Settele, J., Schweiger, O., Murray, T.E., et al. (2017). The structure of flower visitor networks in relation to pollination across an agricultural to urban gradient. Funct. Ecol., 31, 838-847.

Trøjelsgaard, K., Jordano, P., Carstensen, D.W. \& Olesen, J.M. (2015). Geographical variation in mutualistic networks: Similarity, turnover and partner fidelity. Proc. R. Soc. B Biol. Sci., 282, 20142925.

Tylianakis, J.M. \& Morris, R.J. (2017). Ecological networks across environmental 


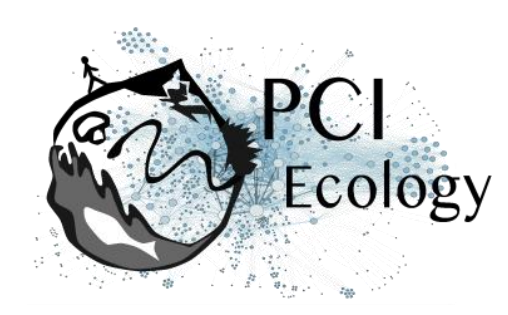

gradients. Annu. Rev. Ecol. Evol. Syst., 48, 25-48.

Valverde, J., Gómez, J.M. \& Perfectti, F. (2016). The temporal dimension in individualbased plant pollination networks. Oikos, 125, 468-479.

Vázquez, D.P., Chacoff, N.P. \& Cagnolo, L. (2009). Evaluating multiple determinants of the structure of plant-animal mutualistic networks. Ecology, 90, 2039-2046.

Vehtari, A., Gelman, A. \& Gabry, J. (2017). Practical Bayesian model evaluation using leave-one-out cross-validation and WAIC. Stat. Comput., 27, 1413-1432.

Westphal, C., Bommarco, R., Carré, G., Lamborn, E., Morison, M., Petanidou, T., et al. (2008). Measuring bee diversity in different European habitats and biogeographic regions. Ecol. Monogr., 78, 653-671.

Willmer, P. (2012). Ecology: Pollinator-plant synchrony tested by climate change. Curr. Biol., 22, R131-R132.

\section{Appendix}

The following Supporting Information is available for this article:

Figure S1. Sites location in France.

Figure S2. Block clustering provided by LBM in the site of Bois de Fontaret (BF, Occitanie), overlaid on a heatmap of species phenology overlap.

Figure S3. Block clustering provided by LBM in the site of Falaises (FAL, Normandie), overlaid on a heatmap of species phenology overlap.

Figure S4. Block clustering provided by LBM in the site of Larris (LAR, Hauts-de-France), overlaid on a heatmap of species phenology overlap.

Figure S5. Block clustering provided by LBM in the site of Riez ( $R$, Hauts-de-France), overlaid on a heatmap of species phenology overlap.

Table S1. Table of transformed plant abundances.

Table S2. Table of hoverfly and plant species names and abbreviations used in the LBM Figures.

Table S3. Table of model accuracy.

Appendix S1. Model code.

Appendix S2. Model script for the 16 models.

Appendix S3. Script modularity and latent block model analysis (LBM). 

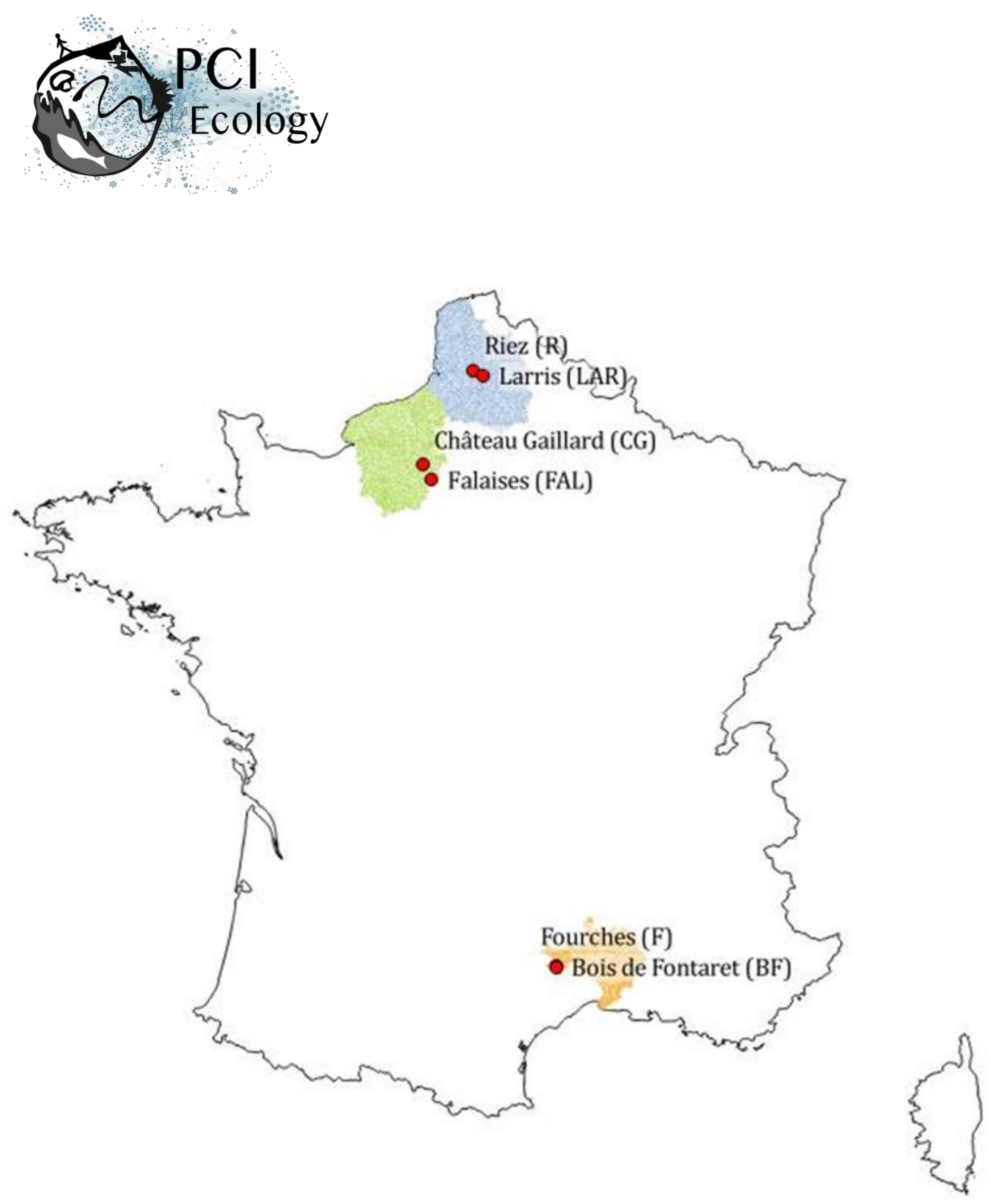

Figure S1. Site location in France: in blue the French départements Pas-de-Calais and Somme (Hauts-de-France region), in green the départements Eure and Seine Maritime (Normandie region), in orange the départment Gard (Occitanie region). The six sites correspond to the red dots (with the sites of Fourches and Bois de Fontaret represented by the same dot due to their closeness). 

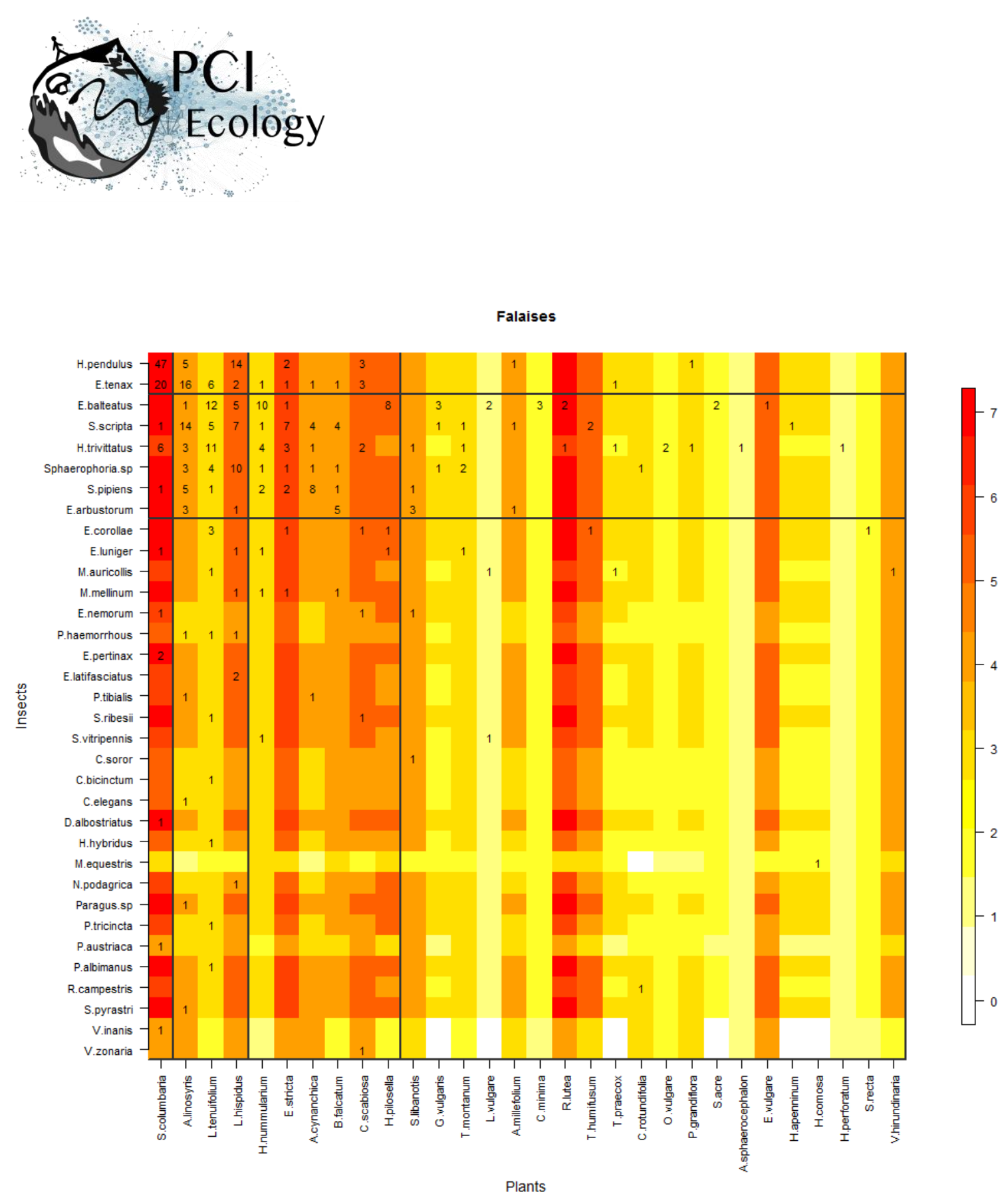

Figure S2. Block clustering provided by LBM in the site of Falaises (FAL, Normandie), overlaid on a heatmap of species phenology overlap. Insect species are displayed in rows and plant species in columns, following their degree (number of partners). The blocks of insects and the blocks of plants are separated by solid black lines. Colours correspond to the number of months that are shared by each pair of plant and insect species (PO, phenology overlap), with higher PO corresponding to darker colours. Numbers are the number of visits observed in the field for a given plant-insect pair. Complete species names are reported in Table S2. 

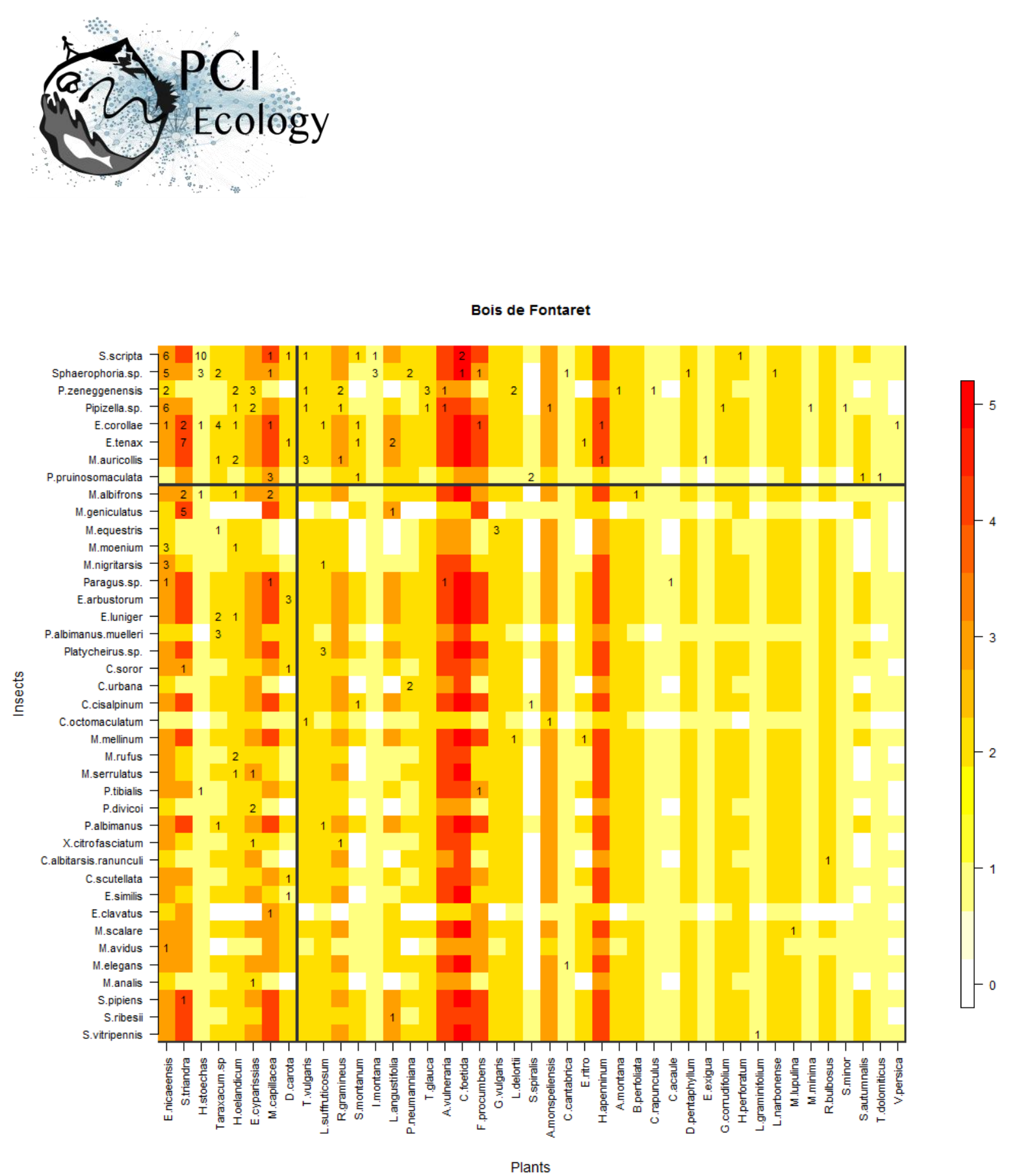

Figure S3. Block clustering provided by LBM in the site of Bois de Fontaret (BF, Occitanie), overlaid on a heatmap of species phenology overlap. Insect species are displayed in rows and plant species in columns, following their degree (number of partners). The blocks of insects and the blocks of plants are separated by solid black lines. Colours correspond to the number of months that are shared by each pair of plant and insect species (PO, phenology overlap), with higher PO corresponding to darker colours. Numbers are the number of visits observed in the field for a given plant-insect pair. Complete species names are reported in Table S2. 

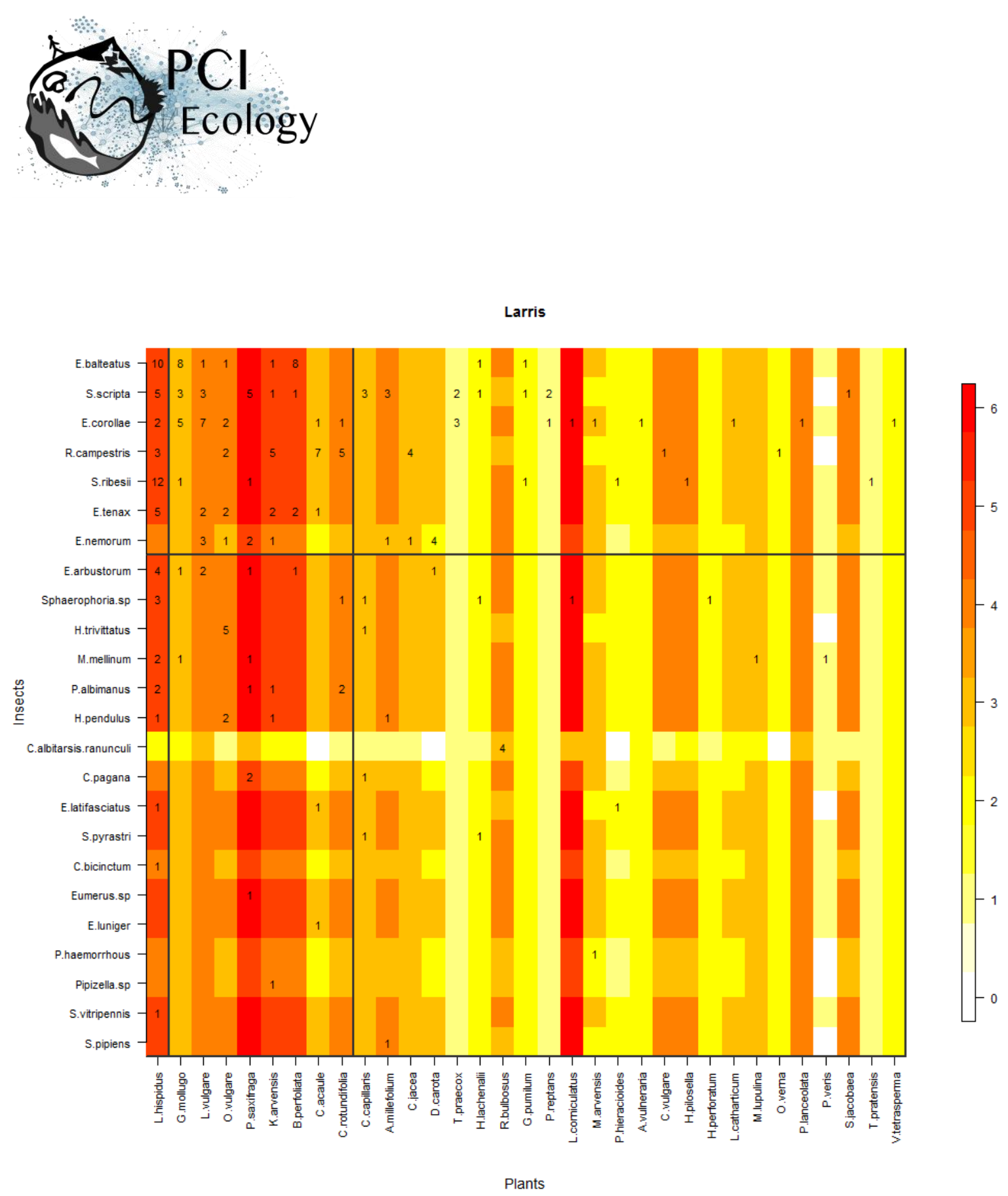

Figure S4. Block clustering provided by LBM in the site of Larris (LAR, Hauts-de-France), overlaid on a heatmap of species phenology overlap. Insect species are displayed in rows and plant species in columns, following their degree (number of partners). The blocks of insects and the blocks of plants are separated by solid black lines. Colours correspond to the number of months that are shared by each pair of plant and insect species (PO, phenology overlap), with higher PO corresponding to darker colours. Numbers are the number of visits observed in the field for a given plant-insect pair. Complete species names are reported in Table S2. 

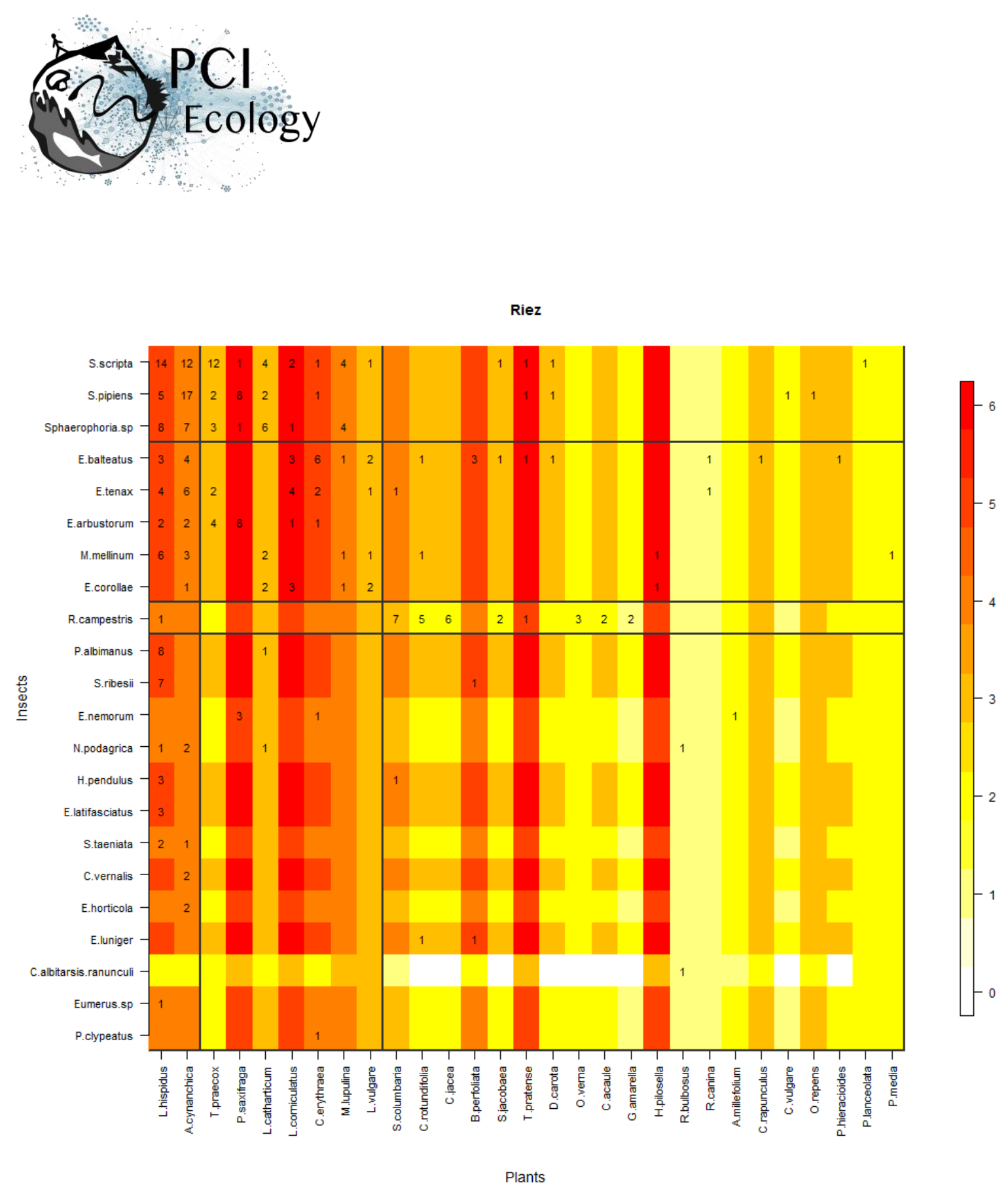

Figure S5. Block clustering provided by LBM in the site of Riez (R, Hauts-de-France), overlaid on a heatmap of species phenology overlap. Insect species are displayed in rows and plant species in columns, following their degree (number of partners). The blocks of insects and the blocks of plants are separated by solid black lines. Colours correspond to the number of months that are shared by each pair of plant and insect species (PO, phenology overlap), with higher PO corresponding to darker colours. Numbers are the number of visits observed in the field for a given plant-insect pair. Complete species names are reported in Table S2. 


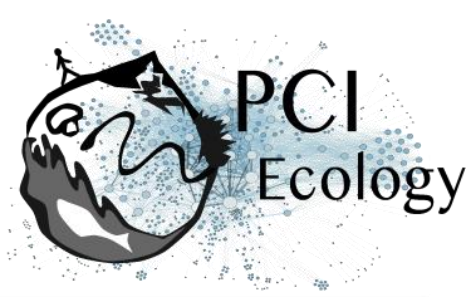

Table S1. Table of transformed plant abundances. The first column shows the Braun-Blanquet coefficients of, the second column, their percentages, and the third column, the transformed abundances used as the plant abundances in the model.

\begin{tabular}{|c|c|c|}
\hline $\begin{array}{c}\text { Coefficient Braun- } \\
\text { Blanquet }\end{array}$ & $\begin{array}{c}\text { Abundance percentage } \\
\text { interval }\end{array}$ & $\begin{array}{c}\text { Abundance } \\
\text { percentage }\end{array}$ \\
\hline$i$ & 1 individual & $0.1 \%$ \\
\hline+ & $<1 \%$ & $0.5 \%$ \\
\hline 1 & $1-10 \%$ & $5 \%$ \\
\hline 2 & $10-25 \%$ & $15 \%$ \\
\hline 3 & $25-50 \%$ & $35 \%$ \\
\hline 4 & $50-75 \%$ & $65 \%$ \\
\hline 5 & $75-100 \%$ & $85 \%$ \\
\hline
\end{tabular}

Table S2. Table of hoverfly and plant species names and abbreviations used in the LBM Figures.

\begin{tabular}{llll} 
Type & Short name & Scientific name & Notes \\
\hline Syrphidae & C.albitarsis.ranunculi & $\begin{array}{l}\text { Cheilosia albitarsis (Meigen), 1822 / } \\
\text { Cheilosia ranunculi (Doczkal), 2000 }\end{array}$ & $\begin{array}{l}\text { the identification is not } \\
\text { possible, could be both } \\
\text { species - in the analysis } \\
\text { we used as one species }\end{array}$ \\
Syrphidae & C.pagana & Cheilosia pagana (Meigen), 1822 & \\
Syrphidae & C.scutellata & Cheilosia scutellata (Fallen), 1817 & \\
Syrphidae & C.soror & Cheilosia soror (Zetterstedt), 1843 & \\
Syrphidae & C.urbana & Cheilosia urbana (Meigen), 1822 & \\
Syrphidae & C.vernalis & Cheilosia vernalis (Fallen), 1817 & \\
Syrphidae & C.bicinctum & Chrysotoxum bicinctum (L.), 1758 & \\
Syrphidae & C.cautum & Chrysotoxum cautum (Harris), 1776 & \\
Syrphidae & C.cisalpinum & Chrysotoxum cisalpinum (Rondani), 1845 & \\
Syrphidae & C.elegans & Chrysotoxum elegans (Loew), 1841 & \\
Syrphidae & C.octomaculatum & Chrysotoxum octomaculatum (Curtis), 1837 & \\
Syrphidae & D.albostriatus & Dasysyrphus albostriatus (Fallen), 1817 & \\
Syrphidae & E.balteatus & Episyrphus balteatus (De Geer), 1776 & \\
Syrphidae & E.arbustorum & Eristalis arbustorum (L.), 1758 & \\
Syrphidae & E.horticola & Eristalis horticola (De Geer), 1776 & \\
Syrphidae & E.nemorum & Eristalis nemorum (L.), 1758 & \\
Syrphidae & E.pertinax & Eristalis pertinax (Scopoli), 1763 & \\
Syrphidae & E.similis & Eristalis similis (Fallen), 1817 & \\
Syrphidae & E.tenax & Eristalis tenax (L.), 1758 & \\
Syrphidae & E.clavatus & Eumerus clavatus (Becker), 1923 &
\end{tabular}




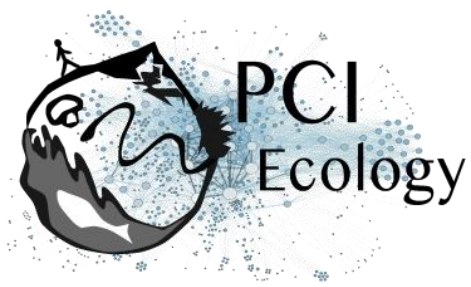

\begin{tabular}{|c|c|c|}
\hline Syrphidae & Eumerus sp. & Eumerus sp. \\
\hline Syrphidae & E.corollae & Eupeodes corollae (Fabricius), 1794 \\
\hline Syrphidae & E.latifasciatus & Eupeodes latifasciatus (Macquart), 1829 \\
\hline Syrphidae & E.luniger & Eupeodes luniger (Meigen), 1822 \\
\hline Syrphidae & F.aurea & Ferdinandea aurea (Rondani), 1844 \\
\hline Syrphidae & H.hybridus & Helophilus hybridus (Loew), 1846 \\
\hline Syrphidae & H.pendulus & Helophilus pendulus (L.), 1758 \\
\hline Syrphidae & H.trivittatus & Helophilus trivittatus (Fabricius), 1805 \\
\hline Syrphidae & M.mellinum & Melanostoma mellinum (L.), 1758 \\
\hline Syrphidae & M.scalare & Melanostoma scalare (Fabricius), 1794 \\
\hline Syrphidae & Melanostoma sp. & Melanostoma sp. \\
\hline Syrphidae & M.auricollis & Meliscaeva auricollis (Meigen), 1822 \\
\hline Syrphidae & M.albifrons & Merodon albifrons (Meigen), 1822 \\
\hline Syrphidae & M.avidus & Merodon avidus (Rossi), 1790 \\
\hline Syrphidae & M.elegans & Merodon elegans (Hurkmans), 1993 \\
\hline Syrphidae & M.equestris & Merodon equestris (Fabricius), 1794 \\
\hline Syrphidae & M.geniculatus & Merodon geniculatus Strobl, 1909 \\
\hline Syrphidae & M.moenium & Merodon moenium (Wiedemann), 1822 \\
\hline Syrphidae & M.nigritarsis & Merodon nigritarsis Rondani, 1845 \\
\hline Syrphidae & M.rufus & Merodon rufus Meigen, 1838 \\
\hline Syrphidae & M.serratulus & $\begin{array}{l}\text { Merodon serrulatus Wiedemann in Meigen, } \\
1822\end{array}$ \\
\hline Syrphidae & M.analis & Microdon analis (Macquart), 1842 \\
\hline Syrphidae & M.crabroniformis & Milesia crabroniformis (Fabricius), 1775 \\
\hline Syrphidae & M.florea & Myathropa florea (L.), 1758 \\
\hline Syrphidae & N.podagrica & Neoascia podagrica (Fabricius), 1775 \\
\hline Syrphidae & P.haemorrhous & Paragus haemorrhous Meigen, 1822 \\
\hline Syrphidae & P.tibialis & Paragus tibialis (Fallen), 1817 \\
\hline Syrphidae & Paragus sp. & Paragus sp. \\
\hline Syrphidae & P.pruinosomaculata & Pelecocera pruinosomaculata Strobl, 1906 \\
\hline Syrphidae & P.tricincta & Pelecocera tricincta Meigen, 1822 \\
\hline Syrphidae & P.austriaca & Pipiza austriaca Meigen, 1822 \\
\hline Syrphidae & P.divicoi & Pipizella divicoi (Goeldlin), 1974 \\
\hline Syrphidae & P.virens & Pipizella virens (Fabricius), 1805 \\
\hline Syrphidae & P.zeneggenensis & Pipizella zeneggenensis (Goeldlin), 1974 \\
\hline Syrphidae & Pipizella sp. & Pipizella sp. \\
\hline Syrphidae & P.albimanus & Platycheirus albimanus (Fabricius), 1781 \\
\hline Syrphidae & P.albimanus.muelleri & $\begin{array}{l}\text { Platycheirus albimanus (Fabricius), } 1782 \text { / } \\
\text { Platycheirus muelleri (Marcuzzi), } 1941\end{array}$ \\
\hline Syrphidae & P.clypeatus & Platycheirus clypeatus (Meigen), 1822 \\
\hline Syrphidae & P.Platycheirus & Platycheirus sp. \\
\hline Syrphidae & R.campestris & Rhingia campestris Meigen, 1822 \\
\hline Syrphidae & S.dignota & Scaeva dignota (Rondani, 1857) \\
\hline Syrphidae & S.pyrastri & Scaeva pyrastri (L.), 1758 \\
\hline
\end{tabular}

the identification is not possible

the identification is not possible

the identification is not possible

the identification is not possible, could be both species

the identification is not possible 


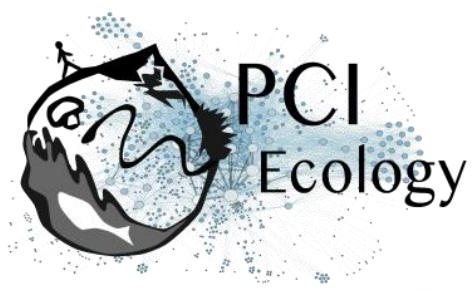

\begin{tabular}{|c|c|c|}
\hline Syrphidae & S.silentis & Sericomyia silentis (Harris), 1776 \\
\hline Syrphidae & S.scripta & Sphaerophoria scripta (L.), 1758 \\
\hline Syrphidae & S.taeniata & Sphaerophoria taeniata (Meigen), 1822 \\
\hline Syrphidae & S.Sphaerophoria & Sphaerophoria sp. \\
\hline Syrphidae & S.pipiens & Syritta pipiens (L.), 1758 \\
\hline Syrphidae & S.ribesii & Syrphus ribesii (L.), 1758 \\
\hline Syrphidae & S.torvus & Syrphus torvus (Osten-Sacken), 1875 \\
\hline Syrphidae & S.vitripennis & Syrphus vitripennis (Meigen), 1822 \\
\hline Syrphidae & V.bombylans & Volucella bombylans (L.), 1758 \\
\hline Syrphidae & V.inanis & Volucella inanis (L.), 1758 \\
\hline Syrphidae & V.pellucens & Volucella pellucens (L.), 1758 \\
\hline Syrphidae & V.zonaria & Volucella zonaria (Poda), 1761 \\
\hline Syrphidae & X.citrofasciatum & $\begin{array}{l}\text { Xanthogramma citrofasciatum (De Geer), } \\
1776\end{array}$ \\
\hline Syrphidae & X.dives & Xanthogramma dives (Rondani), 1857 \\
\hline Plants & A.millefolium & Achillea millefolium \\
\hline Plants & A.genevensis & Ajuga genevensis \\
\hline Plants & A.sphaerocephalon & Allium sphaerocephalon \\
\hline Plants & A.pyramidalis & Anacamptis pyramidalis \\
\hline Plants & A.ramosum & Anthericum ramosum \\
\hline Plants & A.montana & Anthyllis montana \\
\hline Plants & A.vulneraria & Anthyllis vulneraria \\
\hline Plants & A.monspeliensis & Aphyllanthes monspeliensis \\
\hline Plants & A.aggregata & Arenaria aggregata \\
\hline Plants & A.cynanchica & Asperula cynanchica \\
\hline Plants & A.linosyris & Aster linosyris \\
\hline Plants & B.perennis & Bellis perennis \\
\hline Plants & B.laevigata & Biscutella laevigata \\
\hline Plants & B.perfoliata & Blackstonia perfoliata \\
\hline Plants & B.repanda & Brassica repanda \\
\hline Plants & B.falcatum & Bupleurum falcatum \\
\hline Plants & C.patula & Campanula patula \\
\hline Plants & C.rapunculus & Campanula rapunculus \\
\hline Plants & C.rotundifolia & Campanula rotundifolia \\
\hline Plants & C.erythraea & Centaurium erythraea \\
\hline Plants & C.jacea & Centaurea jacea \\
\hline Plants & C.scabiosa & Centaurea scabiosa \\
\hline Plants & C.acaule & Cirsium acaule \\
\hline Plants & C.vulgare & Clinopodium vulgare \\
\hline Plants & C.cantabrica & Convolvulus cantabrica \\
\hline Plants & C.minima & Coronilla minima \\
\hline Plants & C.capillaris & Crepis capillaris \\
\hline Plants & C.foetida & Crepis foetida \\
\hline Plants & C.planiflora & Cuscuta planiflora var. godronii \\
\hline Plants & D.carota & Daucus carota \\
\hline Plants & D.pentaphyllum & Dorycnium pentaphyllum \\
\hline Plants & E.vulgare & Echium vulgare \\
\hline Plants & E.ritro & Echinops ritro \\
\hline
\end{tabular}

the female identification is not possible 


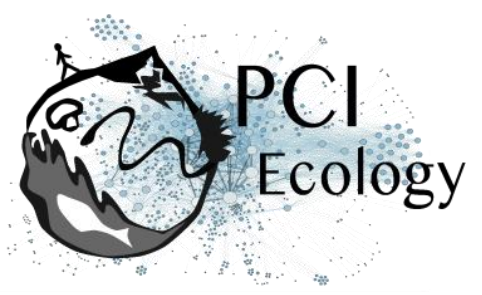

\begin{tabular}{|c|c|c|c|}
\hline Plants & E.atrorubens & Epipactis atrorubens & \\
\hline Plants & E.campestre & Eryngium campestre & \\
\hline Plants & E.cyparissias & Euphorbia cyparissias & \\
\hline Plants & E.esula & Euphorbia esula & \\
\hline Plants & E.exigua & Euphorbia exigua & \\
\hline Plants & E.nicaeensis & Euphorbia nicaeensis & \\
\hline Plants & E.stricta & Euphrasia stricta & \\
\hline Plants & F.ericoides & Fumana ericoides & \\
\hline Plants & F.procumbens & Fumana procumbens & \\
\hline Plants & G.corrudifolium & Galium corrudifolium & \\
\hline Plants & G.mollugo & Galium mollugo & \\
\hline Plants & G.pumilum & Galium pumilum & \\
\hline Plants & G.amarella & Gentianella amarella & \\
\hline Plants & G.vulgaris & Globularia vulgaris & \\
\hline Plants & G.conopsea & Gymnadenia conopsea & \\
\hline Plants & H.apenninum & Helianthemum apenninum & \\
\hline Plants & H.nummularium & Helianthemum nummularium & \\
\hline Plants & H.oelandicum & Helianthemum oelandicum & \\
\hline Plants & H.stoechas & Helichrysum stoechas & \\
\hline Plants & H.lachenalii & Hieracium lachenalii & \\
\hline Plants & H.pilosella & Hieracium pilosella (synonyms) & $\begin{array}{l}\text { Pilosella officinarum } \\
\text { (accepted name) }\end{array}$ \\
\hline Plants & H.comosa & Hippocrepis comosa & \\
\hline Plants & H.perforatum & Hypericum perforatum & \\
\hline Plants & I.montana & Inula montana & \\
\hline Plants & K.arvensis & Knautia arvensis & \\
\hline Plants & L.angustifolia & Lavandula angustifolia & \\
\hline Plants & L.hispidus & Leontodon hispidus & \\
\hline Plants & L.graminifolium & Leucanthemum graminifolium & \\
\hline Plants & L.vulgare & Leucanthemum vulgare & \\
\hline Plants & L.catharticum & Linum catharticum & \\
\hline Plants & L.narbonense & Linum narbonense & \\
\hline Plants & L.tenuifolium & Linum tenuifolium & \\
\hline Plants & L.corniculatus & Lotus corniculatus & \\
\hline Plants & L.delortii & Lotus delortii & \\
\hline Plants & M.lupulina & Medicago lupulina & \\
\hline Plants & M.minima & Medicago minima & \\
\hline Plants & M.capillacea & Minuartia capillacea & \\
\hline Plants & M.rostrata & Minuartia rostrata & \\
\hline Plants & M.arvensis & Myosotis arvensis & \\
\hline Plants & O.verna & Odontites verna & \\
\hline Plants & O.supina & Onobrychis supina & \\
\hline Plants & O.natrix & Ononis natrix & \\
\hline Plants & O.repens & Ononis repens & \\
\hline Plants & O.vulgare & Origanum vulgare & \\
\hline Plants & O.angustifolium & Ornithogalum angustifolium & \\
\hline Plants & P.orbiculare & Phyteuma orbiculare & \\
\hline Plants & P.hieracioides & Picris hieracioides & \\
\hline Plants & P.saxifraga & Pimpinella saxifraga & \\
\hline
\end{tabular}




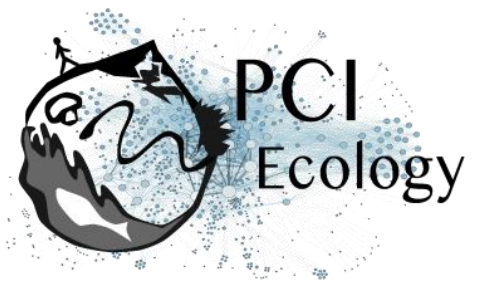

\begin{tabular}{lll} 
Plants & P.lanceolata & Plantago lanceolata \\
Plants & P.media & Plantago media \\
Plants & P.neumanniana & Potentilla neumanniana \\
Plants & P.reptans & Potentilla reptans \\
Plants & P.veris & Primula veris \\
Plants & P.grandiflora & Prunella grandiflora \\
Plants & R.bulbosus & Ranunculus bulbosus \\
Plants & R.gramineus & Ranunculus gramineus \\
Plants & R.lutea & Reseda lutea \\
Plants & R.pumilus & Rhinanthus pumilus \\
Plants & R.canina & Rosa canina \\
Plants & S.minor & Sanguisorba minor \\
Plants & S.columbaria & Scabiosa columbaria \\
Plants & S.triandra & Scabiosa triandra \\
Plants & S.autumnalis & Scilla autumnalis \\
Plants & S.acre & Sedum acre \\
Plants & S.album & Sedum album subsp. micranthum \\
Plants & S.jacobaea & Senecio jacobaea \\
Plants & S.libanotis & Seseli libanotis \\
Plants & S.montanum & Seseli montanum \\
Plants & S.spiralis & Spiranthes spiralis \\
Plants & S.recta & Stachys recta \\
Plants & Taraxacum sp. & Taraxacum sp. \\
Plants & T.montanum & Teucrium montanum \\
Plants & T.humifusum & Thesium humifusum \\
Plants & T.dolomiticus & Thymus dolomiticus \\
Plants & T.praecox & Thymus praecox \\
Plants & T.vulgaris & Thymus vulgaris \\
Plants & T.pratensis & Tragopogon pratensis \\
Plants & T.pratense & Trifolium pratense \\
Plants & T.glauca & Trinia glauca \\
Plants & V.persica & Veronica persica \\
Plants & V.tetrasperma & Vicia tetrasperma \\
Plants & V.hirundinaria & Vincetoxicum hirundinaria \\
\hline Pland &
\end{tabular}




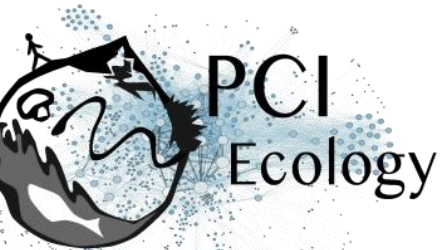

Table S3. Table of model accuracy. The upper part of the table shows the results of the self-validation: in the region Occitanie the self-validation was tested for the site Bois de Fontaret (BF BF) and the site of Fourches (F F); in the region Normandie for the site of Château Gaillard (CG CG) and the sites of Falaises (FAL FAL); and in the region Hauts-de-France for the site of Larris (LAR $\sim$ LAR) and for the site of Riez (R $\sim R$ ). The lower part of the table shows the results of the cross-validation only between each site of the same region: in the region Occitanie between Bois de Fontaret et Fourches (BF F and vice versa F BF); in the region Normandie between the site of Château Gaillard and Falaises (CG FAL and vice versa $F A L \sim C G)$; and in the region Hauts-de-France between the site of Larris and Riez (LAR $\sim R$ and vice versa $R \sim L A R$ ).

\begin{tabular}{|c|c|c|c|c|c|c|c|c|c|}
\hline Model type & Region & Sites & Threshold & $A \cup C$ & $\begin{array}{c}\text { Omission } \\
\text { rate }\end{array}$ & Sensitivity & Specificity & $\begin{array}{c}\text { Prop } \\
\text { correct }\end{array}$ & Kappa \\
\hline \multirow[t]{6}{*}{ Self-validation } & Occitanie & $\mathrm{BF} \sim \mathrm{BF}$ & 0.15 & 0.78 & 0.20 & 0.80 & 0.75 & 0.75 & 0.22 \\
\hline & Occitanie & $F \sim F$ & 0.16 & 0.78 & 0.19 & 0.81 & 0.74 & 0.75 & 0.25 \\
\hline & Normandie & $C G \sim C G$ & 0.44 & 0.75 & 0.29 & 0.71 & 0.79 & 0.78 & 0.34 \\
\hline & Normandie & $\mathrm{FAL} \sim \mathrm{FAL}$ & 0.37 & 0.76 & 0.16 & 0.84 & 0.67 & 0.69 & 0.27 \\
\hline & Hauts-de-France & $\mathrm{LAR} \sim \mathrm{LAR}$ & 0.29 & 0.75 & 0.16 & 0.84 & 0.66 & 0.69 & 0.27 \\
\hline & Hauts-de-France & $R \sim R$ & 0.27 & 0.81 & 0.23 & 0.77 & 0.86 & 0.84 & 0.53 \\
\hline \multirow[t]{6}{*}{ Cross-validation } & Occitanie & $B F \sim F$ & 0.15 & 0.73 & 0.14 & 0.86 & 0.59 & 0.63 & 0.20 \\
\hline & Occitanie & $\mathrm{F} \sim \mathrm{BF}$ & 0.16 & 0.67 & 0.30 & 0.70 & 0.64 & 0.65 & 0.17 \\
\hline & Normandie & $C G \sim F A L$ & 0.44 & 0.62 & 0.45 & 0.55 & 0.70 & 0.67 & 0.21 \\
\hline & Normandie & $\mathrm{FAL} \sim \mathrm{CG}$ & 0.37 & 0.68 & 0.24 & 0.76 & 0.60 & 0.63 & 0.25 \\
\hline & Hauts-de-France & $L A R \sim R$ & 0.29 & 0.63 & 0.35 & 0.65 & 0.61 & 0.61 & 0.17 \\
\hline & Hauts-de-France & $R \sim L A R$ & 0.27 & 0.65 & 0.42 & 0.58 & 0.72 & 0.69 & 0.22 \\
\hline
\end{tabular}




\section{Appendix S1: Model Code}

The model code (in JAGS language) given in this supplementary material refers to the "model Z0" which considers all four parameters (model effects, Table 2 in the main text). Overall, we estimated 16 models that included between 0 and 4 of the above-mentioned effects. To create the code for these other models, parameters should be removed following the order in the Tab. 2. The four parameters tested in the model are: (i) alpha: effect of the phenology overlap (cooc) on the probability of interaction; (ii) epsilon: effect of the phenology overlap on the intensity of visits; (iii) gamma: effect of the insect abundances (ab_l) on the intensity of visits; and (iv) delta: effect of the plant abundances (ab_P) on the intensity of visits.

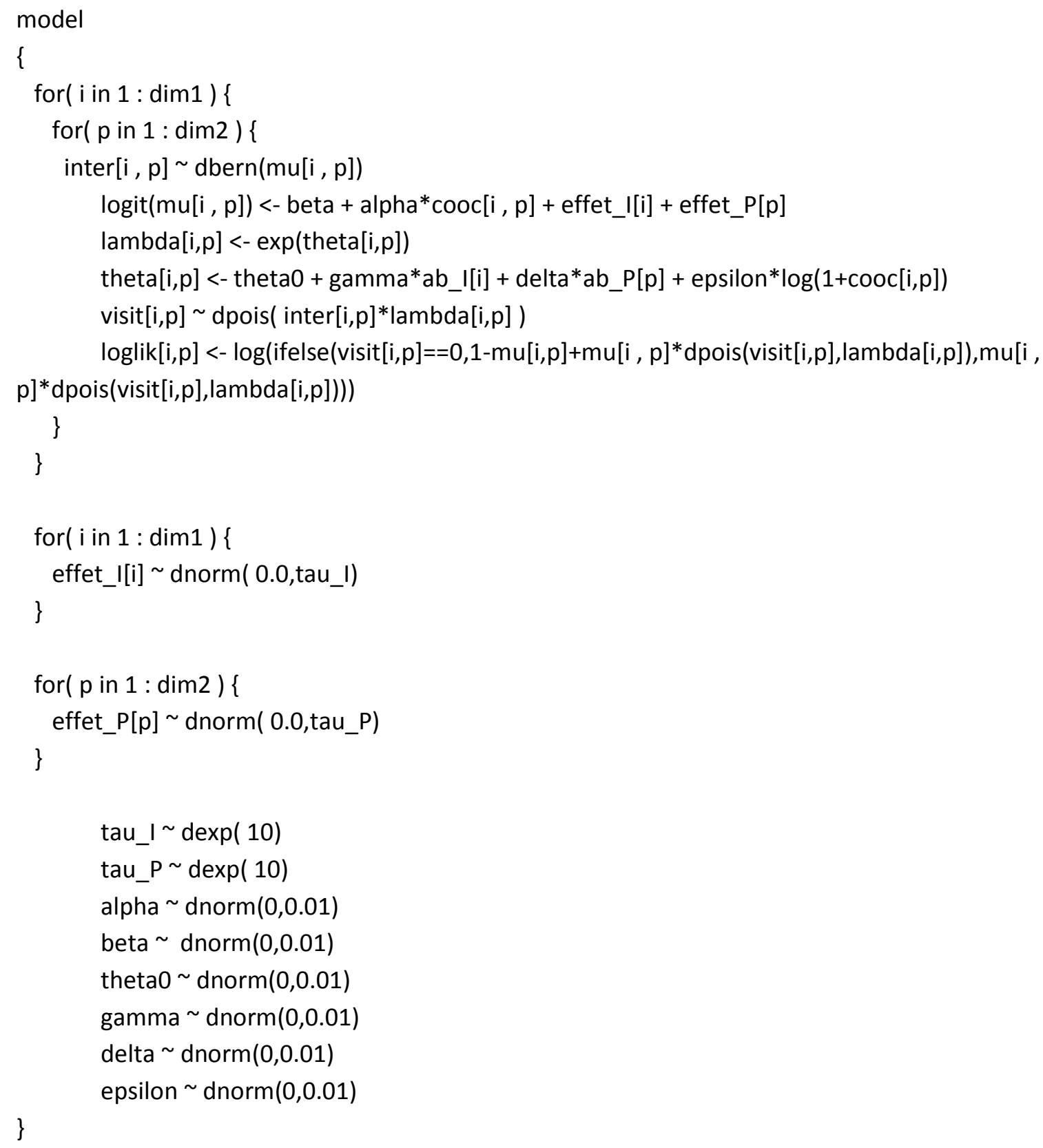

Appendix 2: Model script for the 16 models - LOO values 
The following generic script was applied to all the study sites using all 16 models. The script is separated in three blocks which communicate among them: the script options, the model definitions and the execution (model inference). We defined three options to set (i) the name of the directory (-d), (ii) the site (-s) and (iii) the type of model $(-m)$.

We used, as an example, the information for the site of Bois de Fontaret (BF).

Exemple: Rscript (name) "script-SEMLOO_generique.R" “-d o-BFs-2016" “-s BFs"

In order to calculate the standardised coefficients for each parameters used, at the end of the third block, we added the functions to get the parameter values for each site and each model.

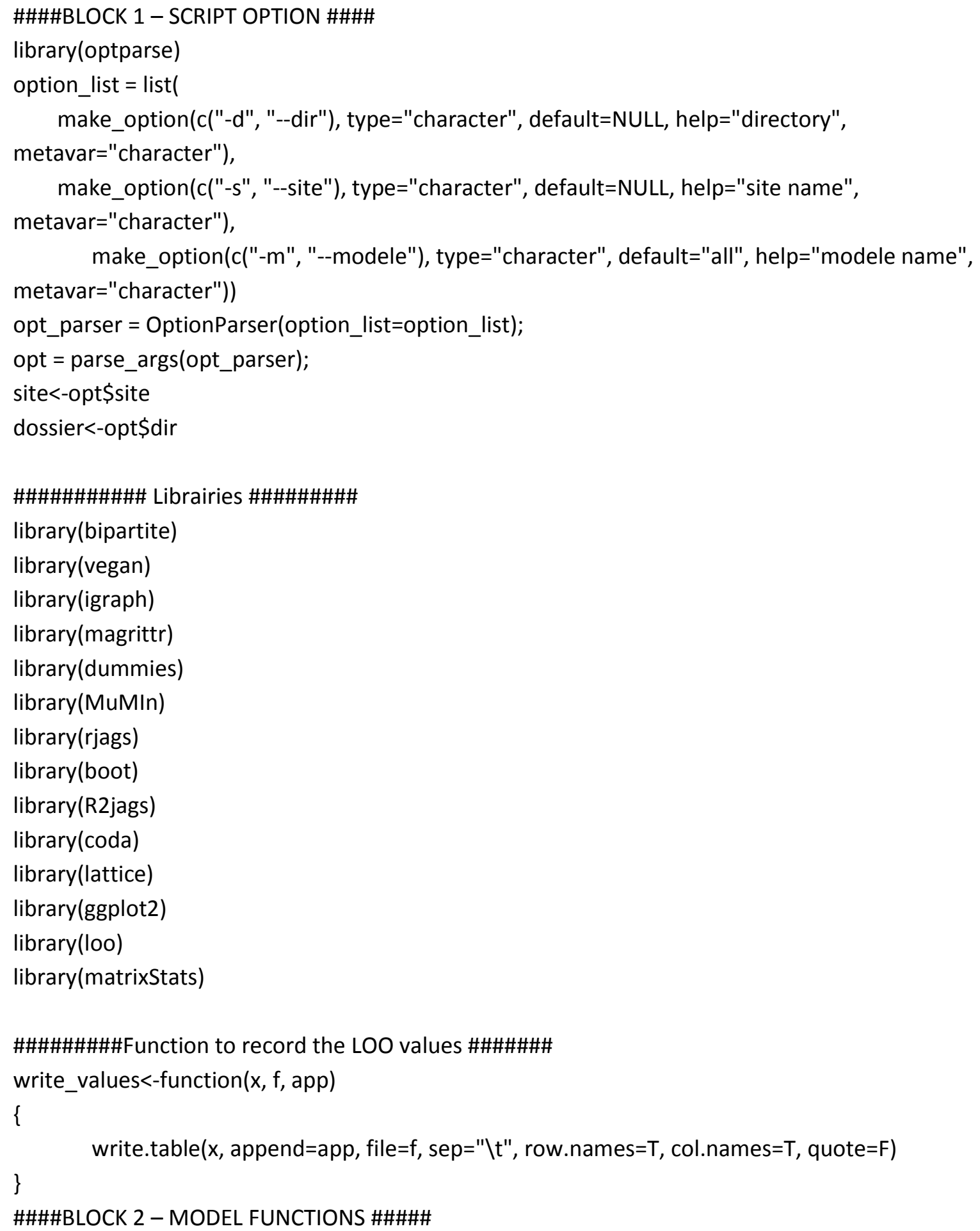


\#Model function and model initialization: one function for each model from model Z15, with 0 parameters, to ZOO with all the parameters\#

\#\#\# MODEL Z015

mZ015<-function()\{

init.funZ015 <-function()\{

list("tau_l" = rexp $(1,10)$, "tau_P" = rexp $(1,10)$, "beta" = rnorm $(1,0,1)$, "theta0" =

rnorm(1,0,1), "effet_l"=rnorm(dim1,0,1),"effet_P"=rnorm(dim2,0,1), "inter"=inter0)

\}

mod.Z015<<-jags(inits=init.funZ015, model.file = "modelZ015_code.txt",data =

list("visit","dim1","dim2"),parameters.to.save =

c("mu","effet_l","effet_P","tau_I","tau_P","beta","theta0", "loglik"),n.chains = 1, n.iter=1000000,

n. burnin $=250000$, n.thin $=250$ )

mod.Z015.mcmc<-as.mcmc(mod.Z015)

mZ015<-mod.Z015\$BUGSoutput\$sims.list

mZ015.deviance<-mZ015\$deviance

mZ015.loglik<-mZ015\$loglik

$\operatorname{dimSEM}<-\operatorname{dim}(m Z 015 . \log l i k)[1]$

list.mZ015<-sapply(1:dimSEM,function(x) matrix(mZ015.loglik[x,,],nrow=dim1*dim2))

list.tmZ015<-(t(list.mZ015))

mZ015.loo<-loo(list.tmZ015)

loo_file<-paste(dossier, "/", site, "_z015_loo.txt", sep="")

write_values("mZ015", app=F, loo_file)

mZ015_loo_pointwise<-mZ015.loo\$pointwise

mZ015_loo_pareto_k<-mZ015.loo\$pareto_k

mZ015.loo\$pareto_k<-NULL

mZ015.loo\$pointwise $<-$ NULL

write_values(as.matrix(mZ015.loo), app=T, loo_file)

save.image(paste(dossier, "/", site, "_Z015.RData", sep=""))

\}

\section{\#\#\# MODEL Z014}

mZ014<-function()\{

init.funZ014 <-function()\{

list("tau_I" = rexp(1,10), "tau_P" = rexp(1,10), "beta" = rnorm(1,0,1), "delta" = rnorm $(1,0,1)$,

"theta0" = rnorm(1,0,1), "effet_I"=rnorm(dim1,0,1),"effet_P"=rnorm(dim2,0,1), "inter"=inter0)

\}

mod.Z014<<-jags(inits=init.funZ014, model.file = "modelZ014_code.txt",data =

list("visit","ab_P","dim1","dim2"), parameters.to.save =

c("mu",,"effet_l","effet_P","tau_I","tau_P","delta","beta","theta0","loglik"),n.chains = 1,

n.iter $=1000000$, n.burnin $=250000$, n.thin $=250$ )

mod.Z014.mcmc<-as.mcmc(mod.Z014)

mZ014<-mod.Z014\$BUGSoutput\$sims.list

mZ014.deviance<-mZ014\$deviance

mZ014.loglik<-mZ014\$ loglik

$\operatorname{dimSEM}<-\operatorname{dim}(m Z 014 . \log l i k)[1]$

list.mZ014<-sapply(1:dimSEM,function(x) matrix(mZ014.loglik[x,,],nrow=dim1*dim2))

list.tmZ014<-(t(list.mZ014)) 


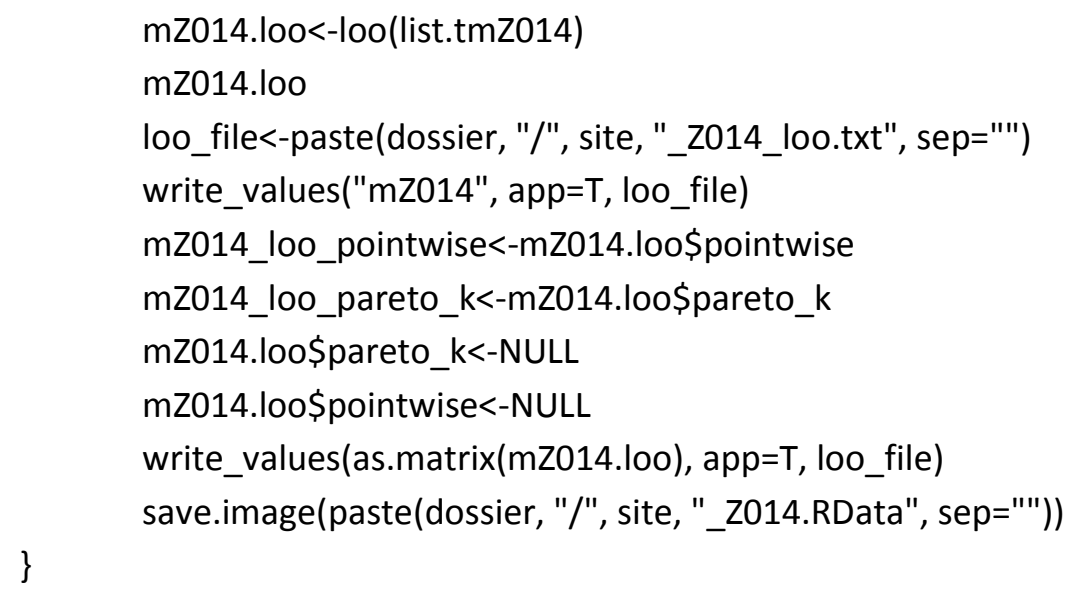


\}

mod.Z012<<-jags(inits=init.funZ012, model.file = "modelZ012_code.txt",data = list("cooc","visit","dim1","dim2"), parameters.to.save =

c("mu","effet_l","effet_P","tau_l","tau_P","beta","theta0","epsilon","loglik"),n.chains = 1,

n. iter $=1000000$, n. burnin $=250000$, n.thin $=250$ )

mod.Z012.mcmc<-as.mcmc(mod.Z012)

mZ012<-mod.Z012\$BUGSoutput\$sims.list

mZ012.deviance<-mZ012\$deviance

mZ012.loglik<-mZ012\$loglik

$\operatorname{dimSEM}<-\operatorname{dim}(m Z 012 . \log l i k)[1]$

list.mZ012<-sapply(1:dimSEM,function(x) matrix(mZ012.loglik[ $\left.\left.\left[x_{,},\right], n r o w=\operatorname{dim} 1 * \operatorname{dim} 2\right)\right)$

list.tmZ012<-(t(list.mZ012))

mZ012.loo<-loo(list.tmZ012)

mZ012.loo

loo_file<-paste(dossier, "/", site, "_Z012_loo.txt", sep="")

write_values("mZ012", app=T, loo_file)

mZ012_loo_pointwise<-mZ012.loo\$pointwise

mZ012_loo_pareto_k<-mZ012.loo\$pareto_k

mZ012.loo\$pareto_k<-NULL

mZ012.loo\$pointwise <-NULL

write_values(as.matrix(mZ012.loo), app=T, loo_file)

save.image(paste(dossier, "/", site, "_Z012.RData", sep=""))

\}

\#\#\# MODEL Z011

mZ011<-function()\{

init.funZ011 <-function()\{

list("tau_l" = rexp(1,10), "tau_P" = rexp(1,10), "alpha" = 0.1,"beta" = rnorm $(1,0,1)$, "theta0"

$=\operatorname{rnorm}(1,0,1)$, "effet_l"=rnorm(dim1,0,1),"effet_P"=rnorm(dim2,0,1), "inter"=inter0)

\}

mod.Z011<<-jags(inits=init.funZ011, model.file = "modelz011_code.txt",data =

list("cooc","visit","dim1","dim2"), parameters.to.save =

c("mu","effet_l","effet_P","tau_I","tau_P","alpha","beta","theta0","loglik"),n.chains = 1,

n. iter $=1000000$, n.burnin $=250000$, n.thin $=250$ )

mod.Z011.mcmc<-as.mcmc(mod.Z011)

mZ011<-mod.Z011\$BUGSoutput\$sims.list

mZ011.deviance<-mZ011\$ deviance

mZ011.loglik<-mZ011\$ loglik

$\operatorname{dimSEM}<-\operatorname{dim}(m Z 011 . \log l i k)[1]$

list.mZ011<-sapply(1:dimSEM,function(x) matrix (mZ011.loglik[ $\left.\left.\mathrm{x}_{,},\right], \mathrm{nrow}=\operatorname{dim} 1 * \operatorname{dim} 2\right)$ )

list.tmZ011<-(t(list.mZ011))

mZ011.loo<-loo(list.tmZ011)

mZ011.loo

loo_file<-paste(dossier, "/", site, "_Z011_loo.txt", sep="")

write_values("mZ011", app=T, loo_file)

mZ011_loo_pointwise<-mZ011.loo\$pointwise

mZ011_loo_pareto_k<-mZ011.loo\$pareto_k 


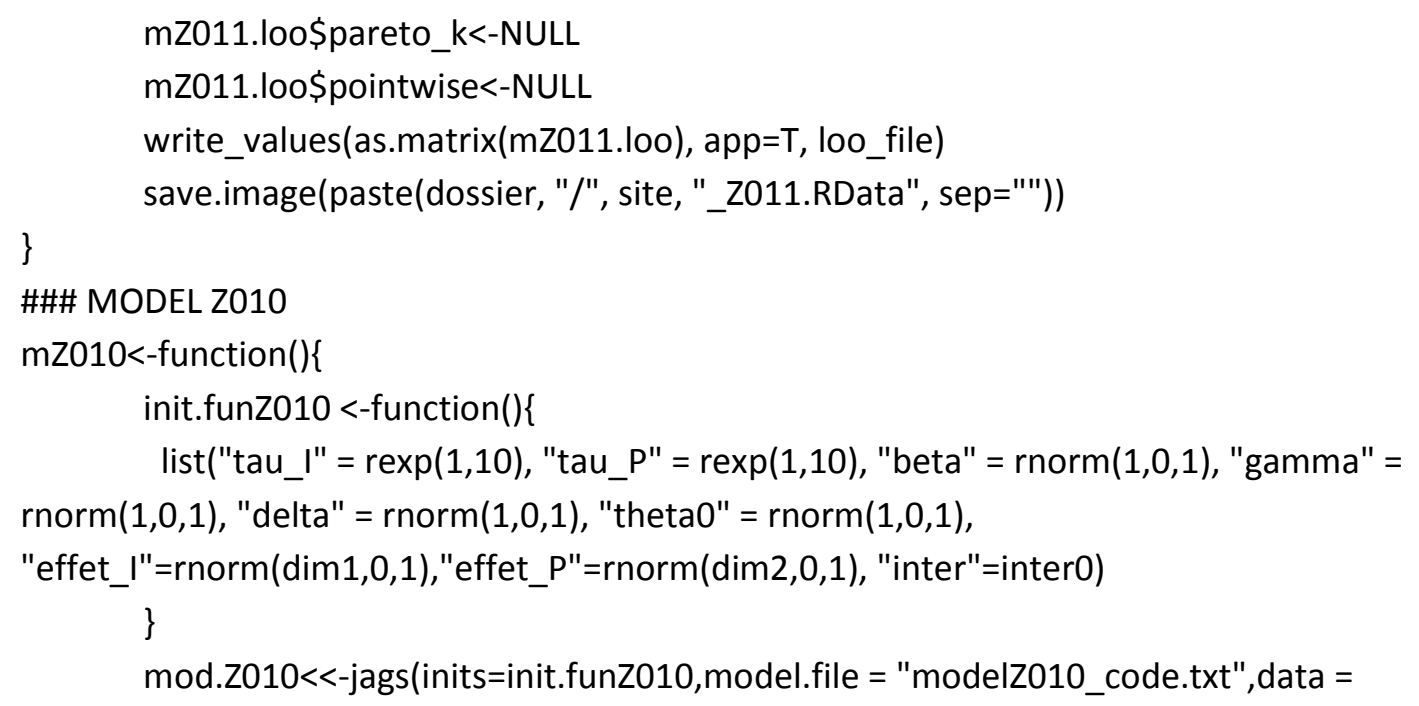




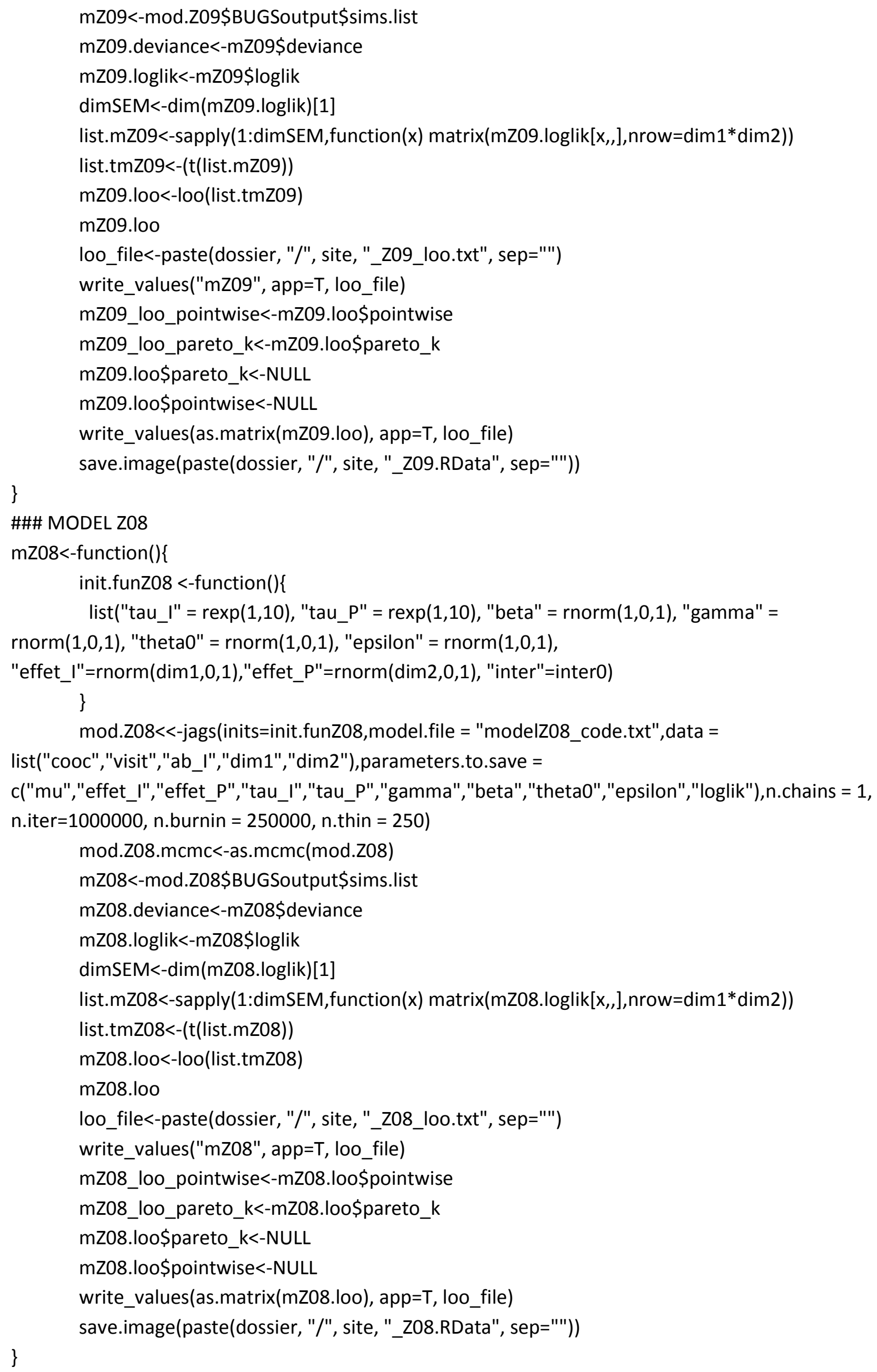




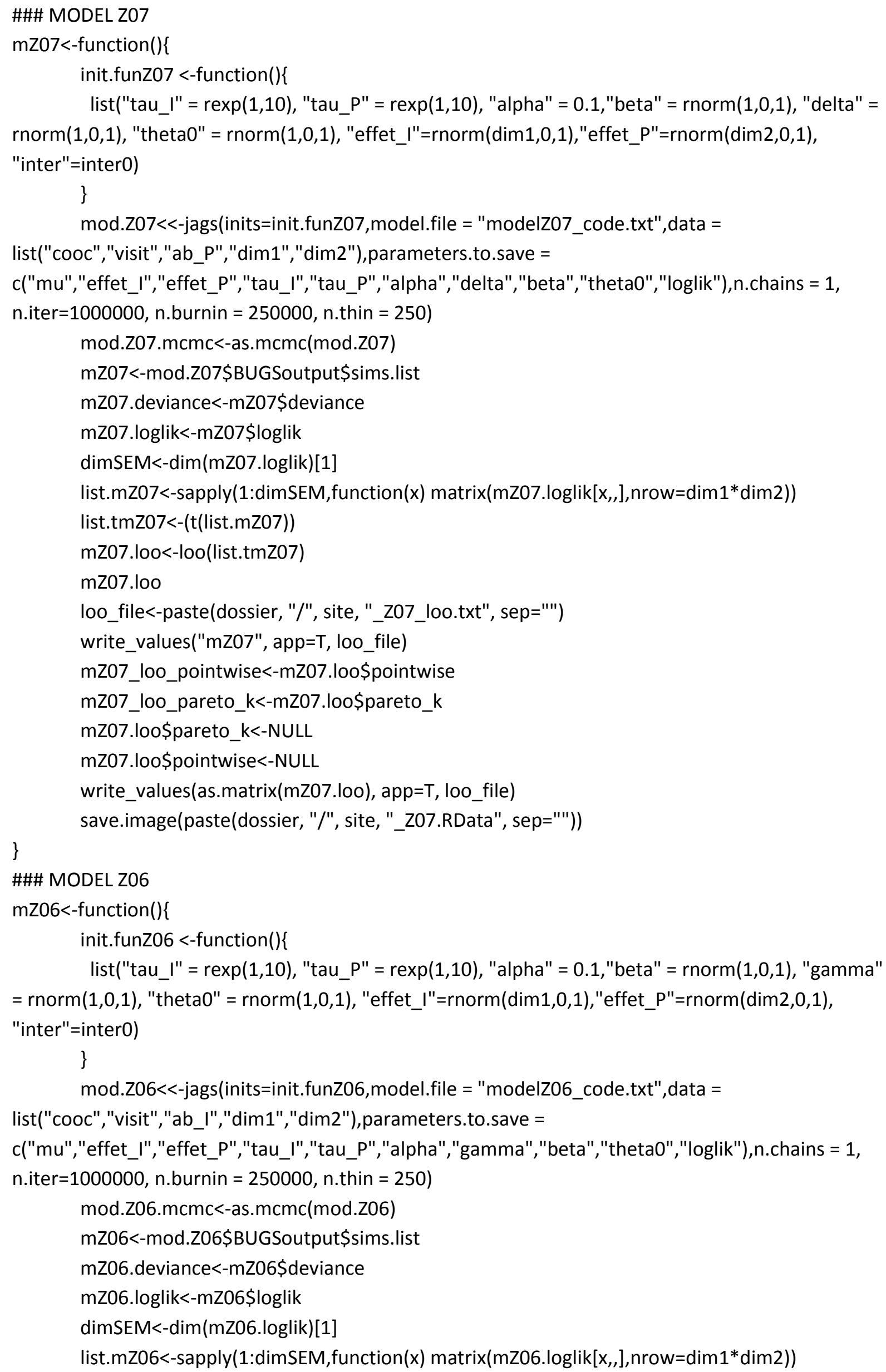




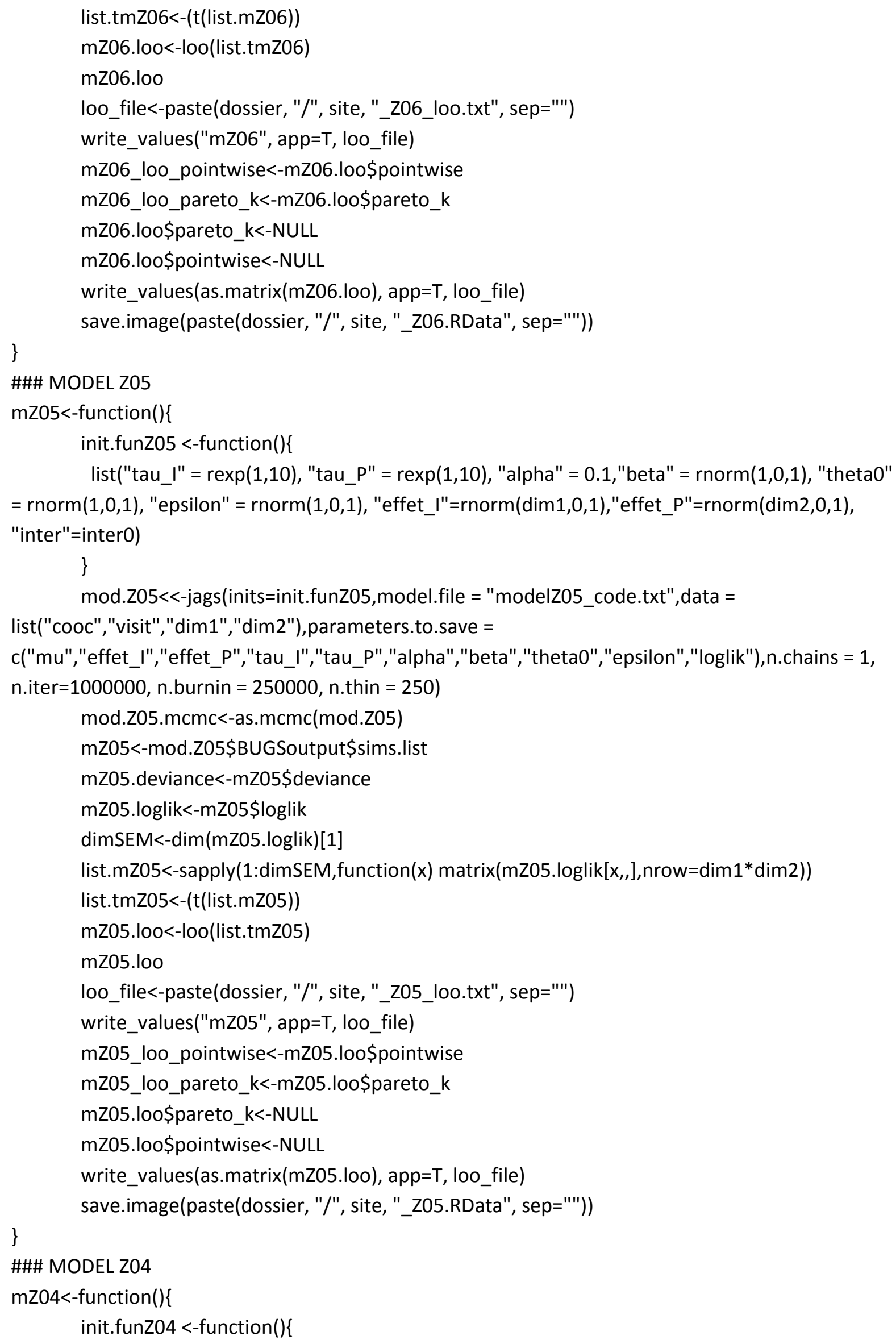


list("tau_I" = rexp(1,10), "tau_P" = rexp(1,10), "beta" = rnorm(1,0,1), "gamma" = rnorm(1,0,1), "delta" = rnorm(1,0,1), "theta0" = rnorm(1,0,1), "epsilon" = rnorm $(1,0,1)$,

"effet_l"=rnorm(dim1,0,1),"effet_P"=rnorm(dim2,0,1), "inter"=inter0)

\}

mod.Z04<<-jags(inits=init.funZ04, model.file = "modelZ04_code.txt",data =

list("cooc", "visit","ab_l","ab_P","dim1","dim2"), parameters.to.save =

c("mu","effet_",,"effet_P","tau_I","tau_P","gamma","delta","'beta","theta0","epsilon","loglik"),n.chai

ns $=1, n \cdot$ iter $=1000000$, n. burnin $=250000$, n.thin $=250$ )

mod.ZO4.mcmc<-as.mcmc(mod.Z04)

mZ04<-mod.Z04\$BUGSoutput\$sims.list

mZ04.deviance<-mZ04\$deviance

mZ04.loglik<-mZ04\$́loglik

$\operatorname{dimSEM}<-\operatorname{dim}(m Z 04 . \log l i k)[1]$

list.mZ04<-sapply(1:dimSEM,function(x) matrix(mZ04.loglik[x,,],nrow=dim1*dim2))

list.tmZ04<-(t(list.mZ04))

mZ04.loo<-loo(list.tmZ04)

mZ04.10o

loo_file<-paste(dossier, "/", site, "_Z04_loo.txt", sep="'")

write_values("mZ04", app=T, loo_file)

mZ04_loo_pointwise<-mZ04.loo\$pointwise

mZ04_loo_pareto_k<-mZ04.loo\$pareto_k

mZ04.loo\$pareto_k<-NULL

mZ04.loo\$pointwise $<-N U L L$

write_values(as.matrix(mZ04.loo), app=T, loo_file)

save.image(paste(dossier, "/", site, "_Z04.RData", sep=""))

\}

\#\#\# MODEL Z03

mZ03<-function()\{

init.funZ03 <-function()\{

list("tau_l" = rexp(1,10), "tau_P" = rexp(1,10), "alpha" = 0.1,"beta" = rnorm(1,0,1), "gamma" $=\operatorname{rnorm}(1,0,1)$, "theta0" = rnorm(1,0,1), "epsilon" = rnorm $(1,0,1)$,

"effet_l"=rnorm(dim1,0,1),"effet_P"=rnorm(dim2,0,1), "inter"=inter0)

\}

mod.Z03<<-jags(inits=init.funZ03, model.file = "modelZ03_code.txt",data =

list("cooc","visit","ab_","dim1","dim2"), parameters.to.save =

c("mu","effet_l","effet_P","tau_l","tau_P","alpha","gamma","beta","theta0","epsilon","loglik"),n.cha

ins $=1$, n.iter $=1000000$, n.burnin $=250000$, n.thin $=250$ )

mod.Z03.mcmc<-as.mcmc(mod.Z03)

mZ03<-mod.Z03\$BUGSoutput\$sims. list

mZ03.deviance<-mZ03\$deviance

mZ03.loglik<-mZ03\$loglik

$\operatorname{dimSEM}<-\operatorname{dim}(m Z 03 . \log l i k)[1]$

list.mZ03<-sapply(1:dimSEM,function( $x)$ matrix(mZ03.loglik[x, ],nrow=dim1*dim2))

list.tmZ03<-(t(list.mZ03))

mZ03.loo<-loo(list.tmz03)

mZ03.10o 


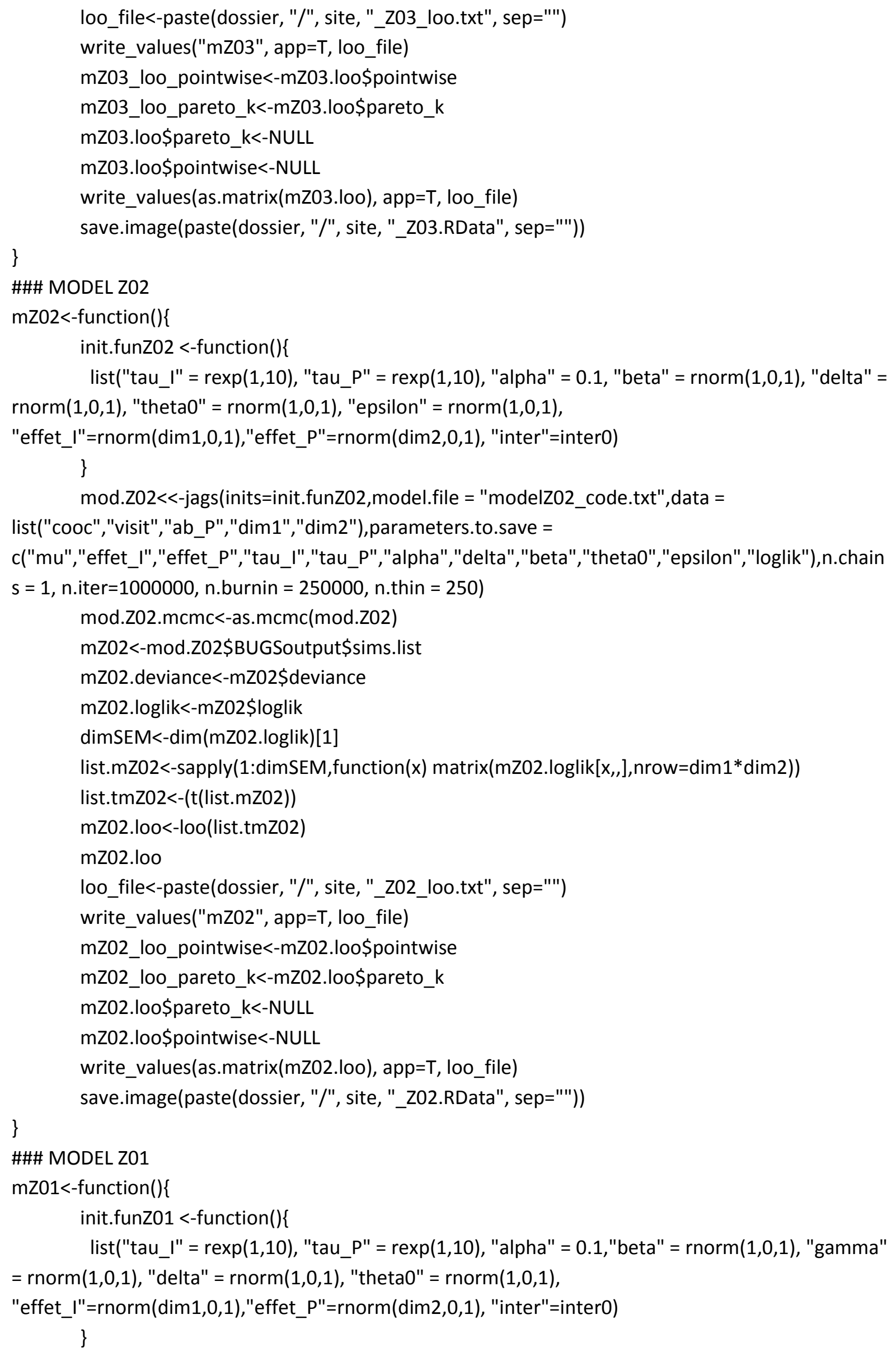


mod.Z01<<-jags(inits=init.funZ01, model.file = "modelZ01_code.txt",data = list("cooc","visit","ab_I","ab_P", "dim1", "dim2"),parameters.to.save =

c("mu",,"effet_l","effet_P","tau_I","tau_P","alpha","gamma","delta","beta","theta0","loglik"),n.chain $s=1$, n.ter $=1000000$, n. burnin $=250000$, n.thin $=250$ )

$\bmod . Z 01 . \mathrm{mcmc}<-$ as. $\mathrm{mcmc}(\bmod . Z 01)$

mZ01<-mod.Z01\$BUGSoutput\$sims.list

mZ01.deviance<-mZ01\$deviance

mZ01.loglik<-mZ01\$̧loglik

$\operatorname{dimSEM}<-\operatorname{dim}(m Z 01 . \log l i k)[1]$

list.mZ01<-sapply(1:dimSEM,function( $\mathrm{x})$ matrix(mZ01.loglik[x,,],nrow=dim1*dim2))

list.tmZ01<-(t(list.mZ01))

mZ01.loo<-loo(list.tmZ01)

mZ01.loo

loo_file<-paste(dossier, "/", site, "_Z01_loo.txt", sep="")

write_values("mZ01", app=T, loo_file)

mZ01_loo_pointwise<-mZ01.loo\$pointwise

mZ01_loo_pareto_k<-mZ01.loo\$pareto_k

mZ01.loo\$pareto_k<-NULL

mZ01.loo\$pointwise $<-N U L L$

write_values(as.matrix(mZ01.loo), app=T, loo_file)

save.image(paste(dossier, "/", site, "_Z01.RData", sep=""))

\}

\#\#\# MODEL ZOO

mZ00<-function()\{

init.funZ00 <-function()\{

list("tau_l" = rexp(1,10), "tau_P" = rexp(1,10), "alpha" = 0.1,"beta" = rnorm(1,0,1), "gamma"

$=\operatorname{rnorm}(1,0,1)$, "delta" = rnorm(1,0,1), "theta0" = rnorm(1,0,1), "epsilon" = rnorm(1,0,1),

"effet_l"=rnorm(dim1,0,1),"effet_P"=rnorm(dim2,0,1), "inter"=inter0)

\}

mod.Z00<<-jags(inits=init.funZ00, model.file = "modelZ00_code.txt",data =

list("cooc","visit","ab_I","ab_P","dim1","dim2"),parameters.to.save =

c("mu","effet_l","effet_P","tau_l","tau_P","alpha","gamma","delta","beta","theta0","epsilon","loglik

"),n.chains $=1$, n.iter $=1000000$, n.burnin $=250000$, n.thin $=250$ )

$\bmod . Z 00 . m c m c<-a s . m c m c(\bmod . Z 00)$

mZ00<-mod.Z00\$BUGSoutput\$sims.list

mZ00.deviance<-mZO0\$deviance

mZ00.loglik<-mZ00\$̊loglik

$\operatorname{dimSEM}<-\operatorname{dim}(m Z 00 . \log l i k)[1]$

list.mZ00<-sapply(1:dimSEM, function( $x)$ matrix (mZ00.loglik[x,], nrow=dim1*dim2))

list.tmZ00<-(t(list.mZ00))

mZO0.loo<-loo(list.tmZ00)

mZO0.loo

loo_file<-paste(dossier, "/", site, "_Z00_loo.txt", sep="")

write_values("mZ00", app=T, loo_file)

mZ00_loo_pointwise<-mZ00.loo\$pointwise

mZ00_loo_pareto_k<-mZ00.loo\$pareto_k 


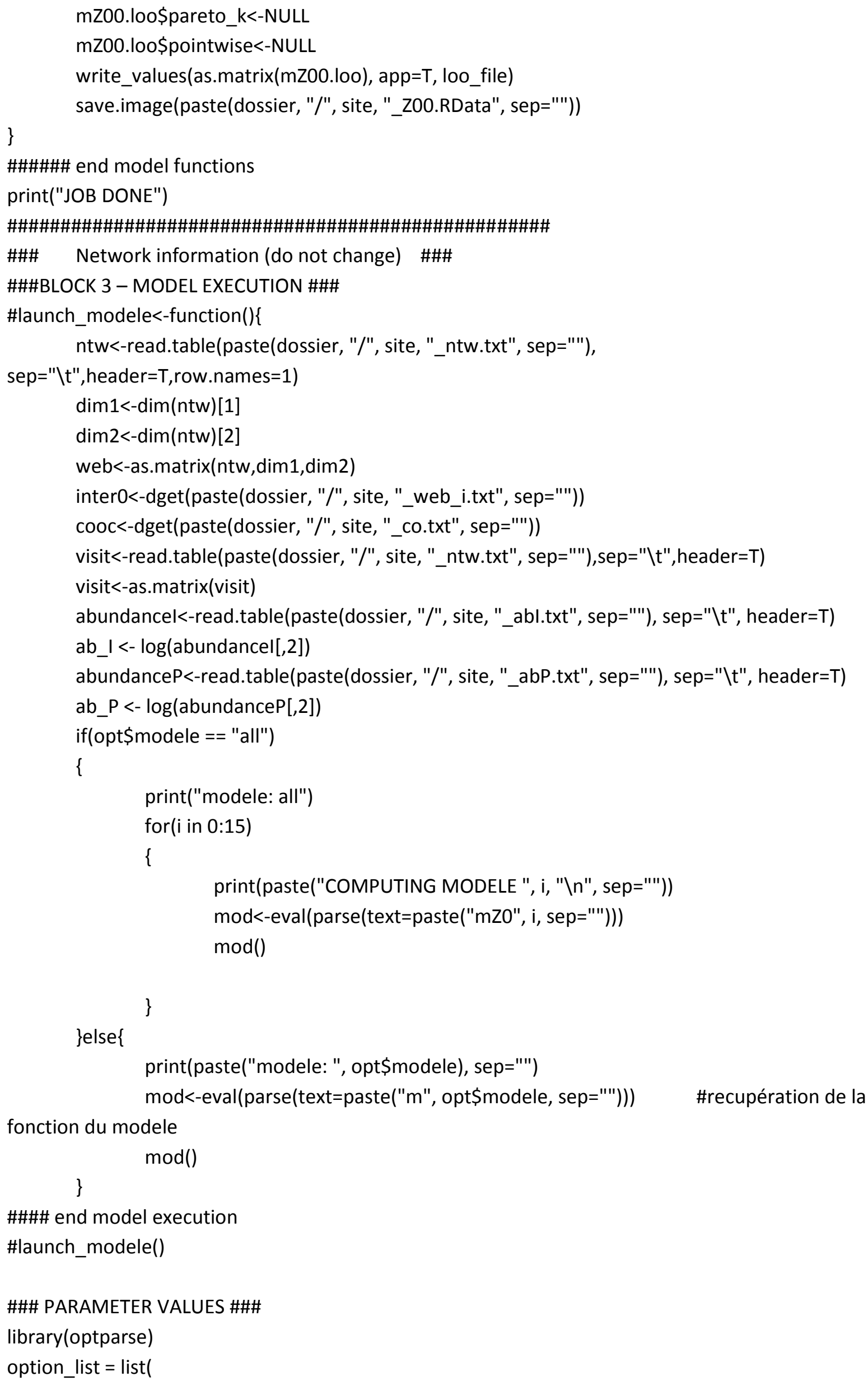


make_option(c("-d", "--dir"), type="character", default=NULL, help="model directory", metavar="character"),

make_option(c("-s", "--site"), type="character", default=NULL, help="site name", metavar="character"))

opt_parser = OptionParser(option_list=option_list);

opt $=$ parse_args(opt_parser);

rdata<-list.files(opt\$ddir, pattern="*_Z015.RData")

load(paste(opt\$dir, "/", rdata, sep="")) \#chargement du RData qui contient tous les modèles pour un site donné

print(paste("RData ", rdata, " loaded", sep="'))

for(mod in Is(pattern="mod.Z0*"))

\{

print(paste("getting values from ", mod, sep=""))

model<-eval(parse(text=mod))

if(is.null(model\$BUGSoutput\$mean\$alpha)) $\{$ model\$BUGSoutput\$mean\$alpha<-NA\}

if(is.null(model\$BUGSoutput\$mean\$beta))\{model\$BUGSoutput\$mean\$beta<-NA\}

if(is.null(model\$BUGSoutput $\$$ mean $\$$ delta)) $\{$ model\$BUGSoutput $\$$ mean $\$$ delta<-NA\}

if(is.null(model\$BUGSoutput\$mean\$epsilon)) \{model\$BUGSoutput\$mean\$epsilon<-NA\}

if(is.null(model\$BUGSoutput $\$$ mean\$gamma)) $\{$ model\$BUGSoutput $\$$ mean\$gamma<-NA\}

val<-matrix(c(model\$BUGSoutput\$mean\$alpha, model\$BUGSoutput\$mean\$beta,

model\$BUGSoutput\$mean\$delta, model\$BUGSoutput\$mean\$epsilon,

model\$BUGSoutput\$mean\$gamma), 1, 5, dimnames=list("values", c("alpha", "beta", "delta",

"epsilon", "gamma")))

write.table(val, file=paste(opt\$dir, "/", opt\$site, "_", mod, "_values.txt", sep="'"), quote=F, sep=" $(t$ ", row.names=F, col.names $=T$ )

\}

\section{Appendix S3: Modularity and latent block model analysis}

We calculated the modularity of the network using the cluster_leading_eigen method for modularity optimization implemented in the igraph package (Csardi and Nepusz 2006, Newman 2006). We then performed latent block models (LBM) using the BM_poisson method for quantitative network data implemented in the blockmodels package (Leger et al. 2015). Blocks are calculated separately for the two groups (insect and plant) based on the number of visits (i.e. a weighted network). The algorithm finds the best divisions of insects and plants through fitting one Poisson parameter in each block of the visit matrix, thus essentially maximizing the ICL (Integrated Completed Likelihood; Biernacki et al. 2000, Daudin et al. 2007).

library(bipartite)

library(vegan)

library(igraph)

library(dummies)

library(blockmodels)

library(ade4) 
library(fields)

\#site data (ex: Bois de Fontaret, BFs)

BFs<-read.table("ntwBFs.txt",header=T,sep=" $t$ ")

webBFs <- as.matrix(BFs)

\#\#\#\#\#\# Modularity analysis, binary data \#\#\#\#\#\#\#\#\#\#\#\#\#

BFs.graph.bin<-graph_from_incidence_matrix(webBFs,multiple=F) \#binary

BFs.bin.cle<-cluster_leading_eigen(BFs.graph.bin)

BFs.bin.cle

\#get phenology overlap matrix

coBF<-dget("coBFs.txt")

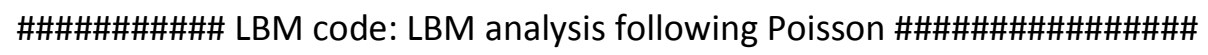

bmi_BFs<-BM_poisson('LBM', webBFs)

bmi_BFs\$estimate()

numi_BFs<-which.max(bmi_BFs\$ICL)

densi_BFs<-sum(webBFs)/(nrow(webBFs)*ncol(webBFs))

probi_BFs<-bmi_BFs\$model_parameters[[numi_BFs]]\$่lambda

row.nb.gpi<-nrow(probi_BFs)

col.nb.gpi<-ncol(probi_BFs)

prob.rowi<-bmi_BFs\$memberships[[numi_BFs]]\$Z1

hh.namei<-rownames(webBFs)

mbrshp.hhi<-apply(prob.rowi,1, which.max)

Is.freq.rowi<-rowSums(webBFs)

res.hhi<-cbind.data.frame(hh.namei=hh.namei, mbrshp.hhi=mbrshp.hhi, freq.hhi=Is.freq.rowi)

res.hh.ordi<-res.hhi[order(res.hhișfreq.hhi),]

$\mathrm{cpt}=0$

for(k in 1: (nrow(res.hh.ordi)-1))

\{

if (res.hh.ordi\$̣mbrshp.hhi[k] !=res.hh.ordi\$̦mbrshp.hhi[k+1]) cpt=cpt+1

\}

nb.diff.hhi=cpt-(length(levels(as.factor(res.hh.ordi\$̇mbrshp.hhi)))-1)

\#write tables

write.table(res.hh.ordi,sep="\t",row.names=FALSE)

prob.coli<-bmi_BFs\$memberships[[numi_BFs]]\$Z2

sp.namei<-colnames(webBFs)

mbrshp.spi<-apply(prob.coli,1, which.max)

Is.freq.coli<-colSums(webBFs)

res.spi<-cbind.data.frame(sp.namei=sp.namei, mbrshp.spi=mbrshp.spi, freq.spi=Is.freq.coli)

res.sp.ordi<-res.spi[order(res.spi\$̧freq.spi),]

$\mathrm{cpt}=0$

for (k in 1: (nrow(res.sp.ordi)-1))

\{

if(res.sp.ordi\$mbrshp.spi[k] !=res.sp.ordi\$mbrshp.spi[k+1]) cpt=cpt+1

\} 
nb.diff.spi=cpt-(length(levels(as.factor(res.sp.ordi\$mbrshp.spi)))-1)

res.sp.ord2i=res.spi[order(res.spi\$mbrshp.spi),]

write.table(res.sp.ordi,sep="\t",row.names=FALSE)

write.table(probi_BFs,file="_prob_BFs",sep="\t",row.names=FALSE)

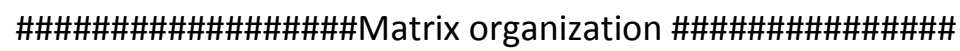

$\operatorname{par}(\operatorname{mfrow}=\mathrm{c}(1,1))$

webBFs2<-webBFs

webBFs[which(webBFs $>1)]=1$

nb.row $=$ nrow (webBFs)

nb.col=ncol(webBFs)

nds=webBFs

$\mathrm{nps}=\mathrm{coBF}$

res.prob=read.table("_prob_BFs",sep="\t",h=TRUE)

Is.ord.col.prob=order(colSums(res.prob), decreasing=TRUE)

Is.ord.row.prob=order(rowSums(res.prob), decreasing=TRUE)

Is.ord.hhi=sapply(res.hhi\$mbrshp.hhi,function(x) which ( $\mathrm{x}==$ =Is.ord.row.prob))

res.hh.ord2i=res.hhi[order(Is.ord.hhi),]

row.nb.gpi=length(levels(as.factor(res.hhi\$mbrshp.hhi)))

res.hh.ord3i=NULL

for (h in Is.ord.row.prob)

\{

part=res.hh.ord2i[res.hh.ord2i\$mbrshp.hhi==h,]

part.ord=part[order(part\$freq.hhi,decreasing=TRUE),]

res.hh.ord3i=rbind.data.frame(res.hh.ord3i,part.ord)

\}

Is.ord.sp=sapply(res.spi\$mbrshp.spi,function( $x$ ) which ( $x==$ Is.ord.col.prob))

res.sp.ord2i=res.spi[order(Is.ord.sp),]

col.nb.gb=length(levels(as.factor(res.spi\$mbrshp.spi)))

res.sp.ord3i=NULL

for (h in Is.ord.col.prob)

\{

part=res.sp.ord2i[res.sp.ord2i\$mbrshp.spi==h,]

part.ord=part[order(part\$freq.spi,decreasing=TRUE),]

res.sp.ord3i=rbind.data.frame(res.sp.ord3i, part.ord)

\}

nds=nds[as.character(res.hh.ord3i\$̧hh.namei),as.character(res.sp.ord3i\$sp.namei)]

nps=nps[as.character(res.hh.ord3i\$hh.namei),as.character(res.sp.ord3i\$sp.namei)]

webBFs2=webBFs2[as.character(res.hh.ord3i\$̧hh.namei),as.character(res.sp.ord3i\$sp.namei)]

\#\#\#\#\#\#\# Plot matrix with heatcolors and the number of visits \#\#\#\#\#\#

visits<-matrix(webBFs2,nrow=dim(webBFs2)[1]*dim(webBFs2)[2],ncol=1)

visits<-visits[which(visits>0)] \#without the zeros

coord.function $<$-function $(x, n l, n P)\{$

$c(((x-1) \% \% n l)+1,((x-1) \% / \% n l)+1)$

\} 


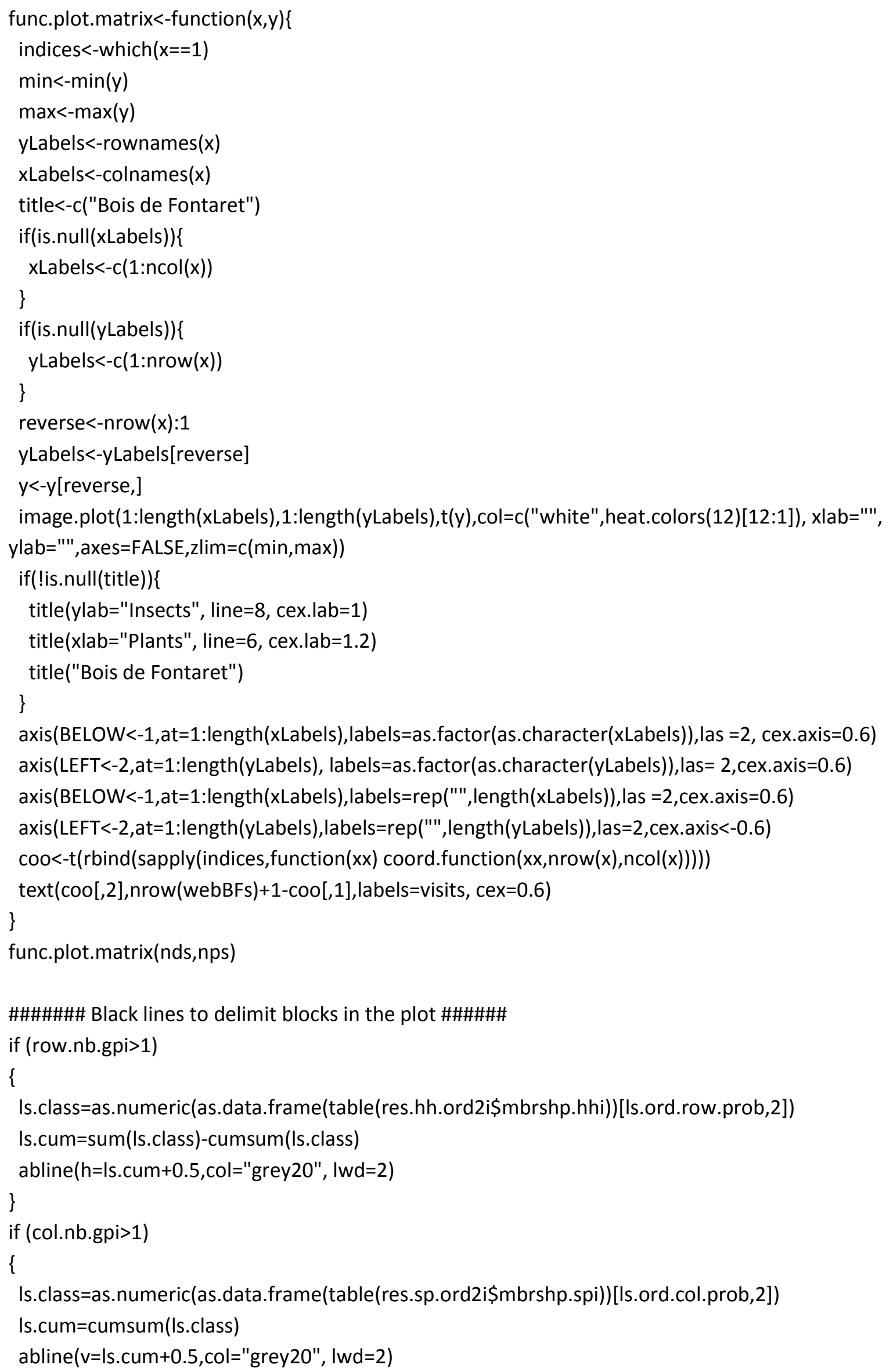

